Research Article

\title{
Effect of Improvement and Application of Composite Prefabricated Vertical Drain Method in Marine Soft Ground: A Case Study
}

\author{
Jianqing Jiang $\mathbb{D}^{1}$ and Reqiang Liu $^{2}$ \\ ${ }^{1}$ Hunan City University, 518 Yingbin Road, Yiyang 413000, China \\ ${ }^{2}$ Guangdong Provincial Architectural Engineering Machinery Construction Company, Guangzhou 510500, China
}

Correspondence should be addressed to Jianqing Jiang; 1h201314@163.com

Received 15 March 2019; Revised 15 May 2019; Accepted 26 May 2019; Published 12 June 2019

Academic Editor: Giovanni Biondi

Copyright (c) 2019 Jianqing Jiang and Reqiang Liu. This is an open access article distributed under the Creative Commons Attribution License, which permits unrestricted use, distribution, and reproduction in any medium, provided the original work is properly cited.

\begin{abstract}
One of the commonly used techniques to improve marine soft ground is the drainage consolidation method by plastic board drains (PBDs). But some complex marine soft ground will cause construction inconvenience of PBDs in certain areas of these sites, thus affecting the improvement effect. An alternative possible approach to overcoming these deficiencies may be the combination of PBDs and sand wick drains (SWDs) (i.e., composite prefabricated vertical drains (CPVDs)) as vertical drainage channels in the same site. In order to verify the suitability and performance of this method in marine soft ground improvement, a case study was performed based on the field monitoring and construction of the marine soft ground of an intercity express railway project in China. The construction procedure using the CPVD system, the field monitoring instrumentation scheme, and the design of fill surcharge level were described, and the field monitoring data were presented. The settlement characteristics, dissipation features of pore water pressure, and the horizontal movement pattern were assessed. In addition, predictions of ultimate settlement, postconstruction settlement, and consolidation degree were discussed by applying a modified hyperbolic model. The results show that the marine ground improved by the CPVD system is suitable for the construction of intercity express railway and high-speed railway. The improvement construction period of complex marine soft ground will be greatly shortened by the proposed parallel construction programme. This work will provide technical supports and application reference for the improvement of the similar marine soft ground.
\end{abstract}

\section{Introduction}

Marine soft soil composed of silt deposits and humus soils was widely distributed in most of the coastal areas around the world, and it was typically characterized by high water content, high porosity, high compressibility, low shear strength, low permeability, low bearing capacity, low coefficient of consolidation, and so on [1-6]. So the bearing capacity and settlement of marine soft soil foundation generally cannot meet the related design specifications. How to improve the marine soft soil foundation rapidly and effectively has been highly focused by the engineering and academic researchers.

One of the most commonly used techniques to improve marine soft ground with a low bearing capacity is prefabricated vertical drains (PVDs) using plastic board drains (PBDs) or sand wick drains (SWDs). Therefore, the prefabricated vertical drains were extensively used to improve marine soft soil sites involving land reclamation, large-scale infrastructural construction for highways, railways, ports, and airports, industrial buildings, and real estate development [7-12]. Moreover, the consolidation process mechanism of PVD-imposed soft soil foundations has been investigated extensively in recent works [13-18].

However, some complex marine soft soil sites often have large ponds, shore embankments, sidewalk road networks, and other facilities. In some areas of these sites, the construction of PBDs will be inconvenient, which will significantly affect the improvement and construction quality. An 
alternative possible approach to overcome these deficiencies may be the combination of PBDs and SWDs (i.e., composite prefabricated vertical drains (CPVDs)) as vertical drainage channels in the same site. But the design and construction experience for the combination of two different kinds of vertical drainage channels to improve large-scale marine soft soil is very scarce.

Therefore, in this paper, an approach of composite prefabricated vertical drains (CPVDs) incorporating fill preloading was proposed to treat marine soft ground. In order to verify the suitability and performance of this method in marine soft ground improvement, a case study was performed based on the field monitoring and construction of the marine soft ground of an intercity express railway project improved by this method in China. The case study results about its settlement characteristics, dissipating feature of pore water pressure, horizontal displacement law, and design and construction procedure were presented. In addition, predictions of its ultimate settlement, postconstruction settlement and consolidation degree were discussed by applying a modified hyperbolic model. It will provide technical supports and application reference for improvement of similar marine soft ground.

\section{Description of Site and Soil Conditions}

The test site is located at a railcar depot of the intercity express rail line approximately $35 \mathrm{~km}$ northeast of the South China Sea entrance of the Pearl River in Guangdong Province, China (as shown in Figure 1). The test site belongs to China Dongjiang delta plain area with mean ground elevation of $2.0 \sim 8.0 \mathrm{~m}$ above the sea level. Some large ponds containing sidewalk networks, with about $2.0 \mathrm{~m}$ average water depth, are distributed in the test site which has power lines across. There are about $500,000 \mathrm{~m}^{2}$ marine soft soil which needs to be improved in the field of railcar depot.

The overlying layer, spreading in the scope of the site, mostly consists of fill soil, quaternary holocene alluvial layer, pleistocene alluvial layer, and quaternary residual layer, and the underlying bedrock is a mixed gneiss of the Daqishan formation in the Sinian system. Both field and laboratory tests as per relevant ASTM standards were conducted for site characterization before the installation of CPVDs. Based on the in situ test data and laboratory test results, the generalized soil physical properties are shown in Table 1 .

The properties of the main soil layers in the foundation of test section are described as follows: (1) mixed backfill soil layer: this layer is in the state of loose-slightly dense and mainly comprised of powdery clay which is randomly mixed with rubble and part of them with earth filling or sand filling; the thickness and depth of this layer is $0.6 \sim 7.0 \mathrm{~m}$ and $0 \sim 2.8 \mathrm{~m}$, respectively; the average standard penetration test (SPT) $\mathrm{N}_{63.5}$ value is 9 blows per $30 \mathrm{~cm}$. (2) Silty soft clay: this layer is in soft plastic condition with gray-yellow and brownyellow and mainly consists of soft clay and silt which is randomly mixed with rubble and part of them with earth filling or sand filling; the thickness and depth of this layer is 0.5 4.9 $\mathrm{m}$ and $0 \sim 5.7 \mathrm{~m}$, respectively. (3) Muddy soft clay: this layer widely distributed within the site is in the state of soft- plastic $\sim$ flow-plastic with dark-gray or black; the thickness and depth of this layer is $0.4 \sim 9.2 \mathrm{~m}$ and $0 \sim 14.2 \mathrm{~m}$, respectively; the average standard penetration test (SPT) $\mathrm{N}_{63.5}$ value is 4.0 blows per $30 \mathrm{~cm}$ and the organic matter content reaches $11.4 \%$ locally. (4) Silty sand: this layer mainly consists of silt, silty soil, powdery sand, and fine sand in dark-gray and brown-gray; the thickness and depth of this layer is $1.1 \sim 13.2 \mathrm{~m}$ and $0 \sim 13.4 \mathrm{~m}$, respectively; the average standard penetration test (SPT) $\mathrm{N}_{63.5}$ value is 4.6 blows per $30 \mathrm{~cm}$.

The average compressive modulus and average compression coefficient of the soft layers (i.e., layers (2), (3), and (4)) are about $2.65 \mathrm{MPa}$ and $1.12 \mathrm{MPa}^{-1}$, respectively. Moreover, the natural water content and the liquidity index of these layers are approximately $85.7 \%$ and 1.8 , respectively. The average of the over consolidation ratio (OCR) of the soil layers is approximately 0.79 . The compression and recompression indices of the soft layers determined by laboratory consolidation tests are concentrated in 0.52 0.89 and $0.05 \sim 0.08$, respectively. It indicates that these layers are in plastic flow state and have higher compressibility, so they can be classified as high compressible soils. As a result, the presence of these soft layers represents an undesirable condition and the soft foundation needs to be improved appropriately before the construction of this express rail line.

\section{Design and Construction Technical Requirements for Drainage System}

3.1. Composite Prefabricated Vertical Drain (CPVD) System. Considering the situation of the site, the PBDs were applied as the vertical drains of soft soil in large pond areas, and the SWDs were used as the vertical drains for the existing sidewalk networks areas, thick filling soil areas, and highvoltage line crossing areas. Moreover, some SWD regions with width of about $15 \mathrm{~m}$ were spread on both sides of the high voltage line area. The PBDs were installed in an equilateral triangular grid of $1.20 \mathrm{~m}$. The sand wells have a diameter of $100 \mathrm{~mm}$ and are also installed in an equilateral triangle layout with center spacing $1.6 \mathrm{~m}$, as shown in Figure 2(b). Since the PVD dimensions controlled the consolidation time, the width and thickness of the plastic board of the PBDs should be sufficient to ensure the discharge capacity [12]. The plastic board of the PBDs used in this case has a thickness of $4.0 \mathrm{~mm}$, a width of $100 \mathrm{~mm}$, and a discharge capacity of $30 \times 10^{-6} \mathrm{~m}^{3} / \mathrm{s}$. The maximum tensile strength of the plastic core of the PBDs is greater than $13 \mathrm{kN} /$ $\mathrm{m}$ at the tensile strain of $10 \%$. The layout of the PBDs and SWDs is shown in Figures 2(a) and 2(e).

Before the PBDs and SWDs were installed, the water in the pond areas was pumped by submersible pumps at first so that the deep marine soft soil could form a hard crust layer with a small thickness. In addition, the original ground of the test site was cleared of grass roots and garbage. Then, a layer of warp-knitted composite geotextile was laid on the surface of the soft ground, and a sand blanket was filled.

The installation of PBDs was implemented by fixing the rig assembly at the desired location. Then, the anchor plate and mandrel with the PBD were driven to the design 


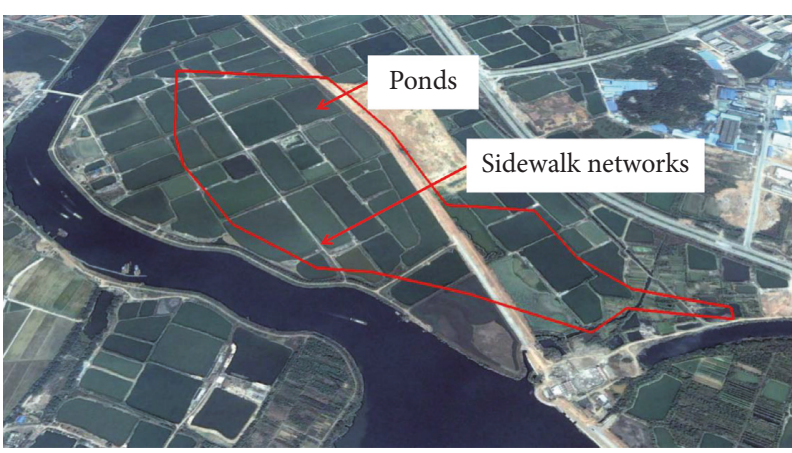

(a)

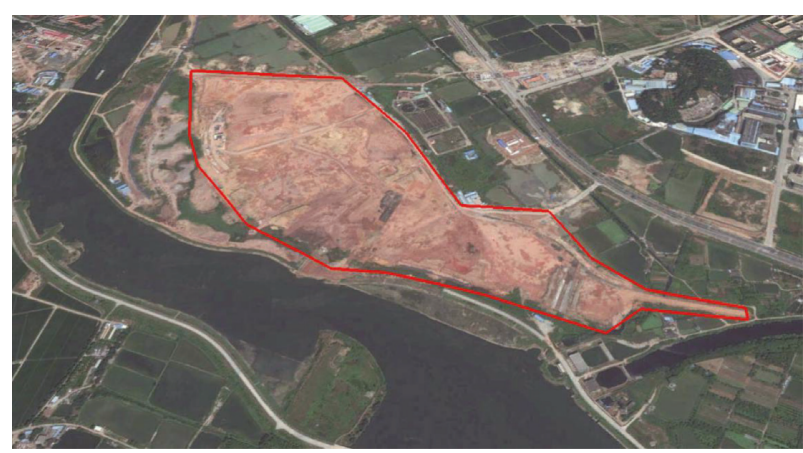

(b)

Figure 1: Test site: (a) and (b) represent the satellite image before and during ground improvement, respectively.

elevation. Subsequently, the mandrel was pulled out and the PBD remains anchored in the place after cutting it $0.20 \mathrm{~m}$ above the surface of the sand blanket. The PBDs were set up from the both ends of the site to the middle at the same time (Figure 2(c)).

The sand material of the SWDs has a clay content of not more than $3 \%$ and a permeability coefficient of more than $1 \times 10^{-4} \mathrm{~m} / \mathrm{s}$. The SWDs penetrated the soft soil layers and embedded into the underlying layer not less than $1.0 \mathrm{~m}$. For the installation of the SWDs, it was constructed by the vibration sinking method. A cylindrical tube with a petalshaped tip or a concrete-end-shoe was sunk to the design elevation using a vibrating hammer, and then the sand bag was injected into the tube. Finally, the tube was pulled out to form a sand-well drainage. The SWDs were divided into three simultaneously constructed groups, and the construction sequence of the three groups is shown in Figure 2(d). After installation of the CPVDs, the average thickness of the sand blanket was increased to $1.5 \mathrm{~m}$.

3.2. Horizontal Drain System. The horizontal drain system composed mainly of some blind trenches was embedded in the sand blanket to collect water to be discharged from the vertical drains. The blind trenches consisting of infiltrated geotextile-wrapped graded crushed-stones were arranged in the sand fill blanket layer at intervals of $60 \mathrm{~m}$ in horizontal and transverse directions. Subsequently, the catchment trench was arranged at the edge of the preloading area for collecting the precompression consolidation drainage water of the marine soft soil ground discharged by the horizontal and vertical drainage system and was drained by some submersible pumps. The permeability coefficient of the sand blanket should be greater than $1 \times 10^{-4} \mathrm{~m} / \mathrm{s}$. The profile of soft ground treatment is indicated in Figure 2(b).

\section{Design and Construction Technical Requirements for Stage Loading Surcharge}

4.1. Filling Method Selection for Surcharge. In the composite prefabricated vertical drains (CPVDs) combined with surcharge preloading method, the PBDs or SWDs are previously installed in different parts of the soft ground and then the soft foundation is preloaded by loading the filling surcharge to add additional stress in soft soil foundation. Two options were considered in the design of the filling method for surcharge: one method was utilizing the dredging vessels to hydraulically fill the submarine sand to the construction site; the other was taking advantage of motor vehicles to transport earth filling. When using the hydraulic filling sand preloading method, it will demand a huge amount of sand (about 2,600,000 $\mathrm{m}^{3}$ ). Moreover, the harbor has a certain distance away from the construction site, which means the power loss is noticeable and it is hard to meet the civilized construction and environmental requirements. Thus, the preloading procedure was loaded by vehicle fill as the final choice.

\subsection{Parallel Construction Sequence for Stage Loading} Surcharge. After installation of the CPVDs, heavy clay was filled atop the vertical and horizontal drain systems to squeeze water out of the deep marine soft soil and consolidate the soft subsoil. For the fill preloading of complex large-scale marine soft ground, it is necessary to perform small-scale fill preloading tests in order to guide the largescale fill preloading construction. However, the fill preloading period is usually relatively long. If the large-scale fill preloading construction is carried out after the completion of the small-scale fill preloading tests, the construction period will be greatly affected and it is difficult to guarantee the normal construction schedule.

In order to shorten the construction period, the construction programme of onsite fill preloading was decided to adopt parallel construction at the small-scale preloading guiding area and the large-scale preloading area. The largescale preloading construction was applied about 30 days after the small-scale preloading guiding area was full loaded in each load level. The concept of parallel construction sequence for stage fill preloading is shown in Figure 3. The monitoring data from the small-scale preloading test area can be used as a construction guide for the large-scale preloading area. If some abnormal situations occurred in the small-scale preloading test area, 30 days has been enough for adjusting the plan for the large-scale preloading construction, thereby reducing the construction risks.

The total surcharge height is $7 \mathrm{~m}$, and the surcharge filling construction was divided into three stages. As shown 


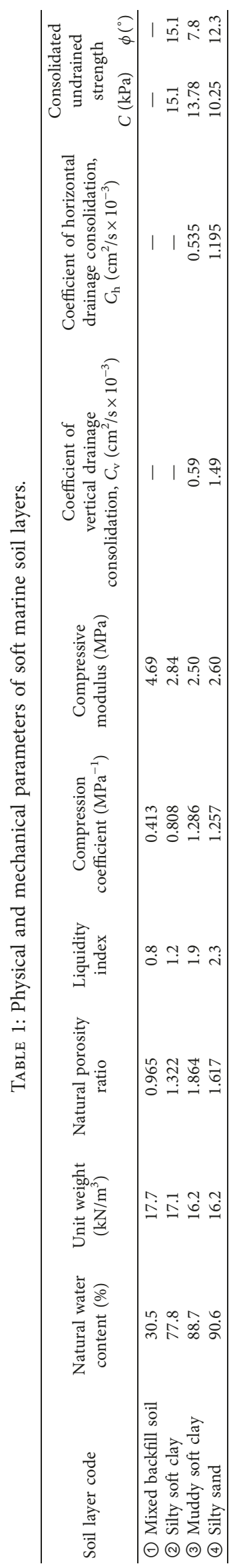




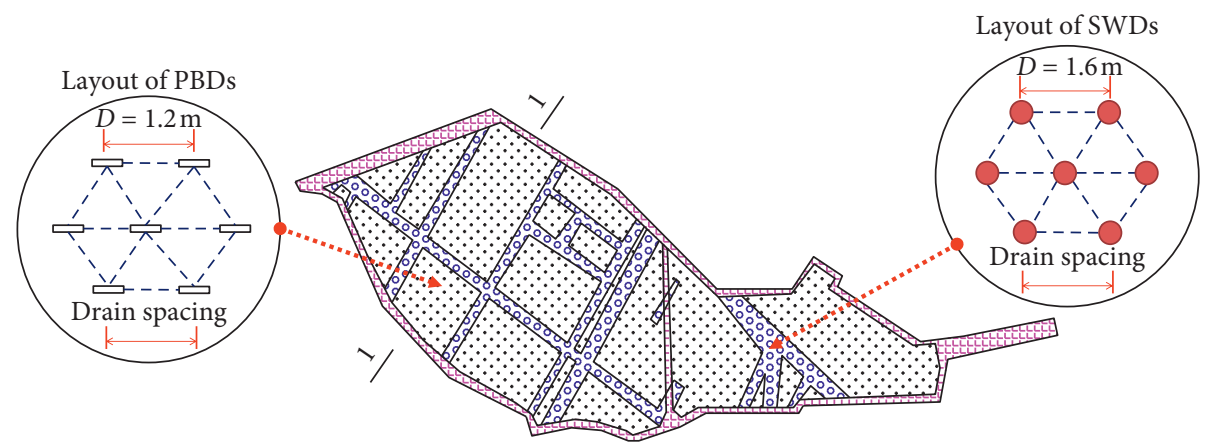

Catchment trench

\%ั0 SWD area

$\because \because$ PBD area

(a)

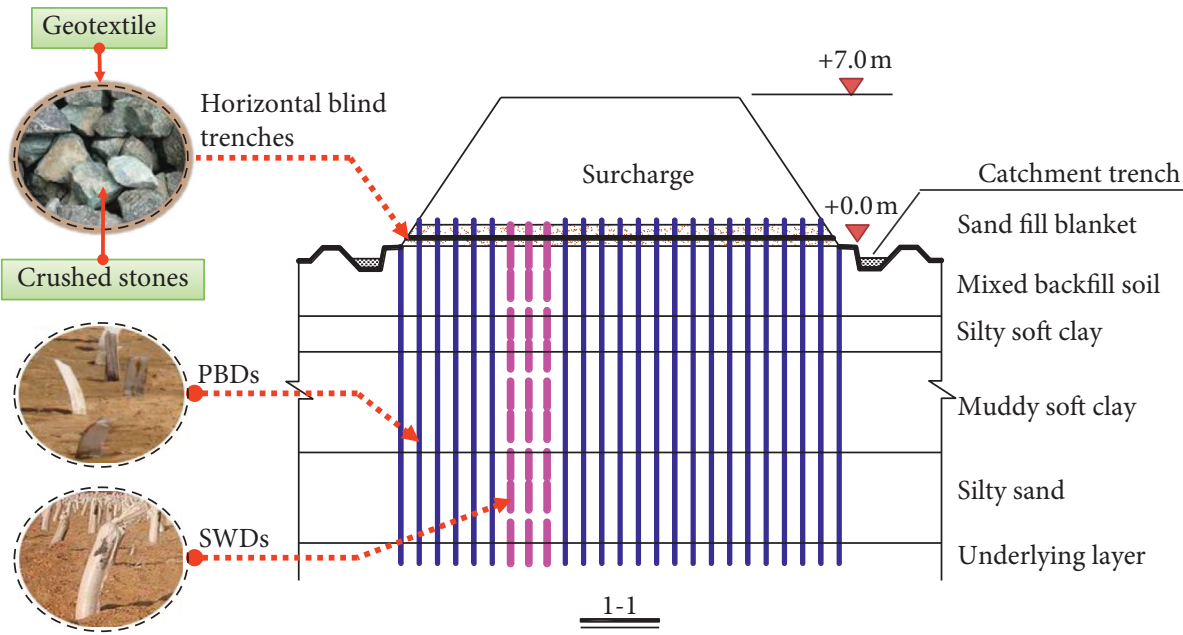

(b)

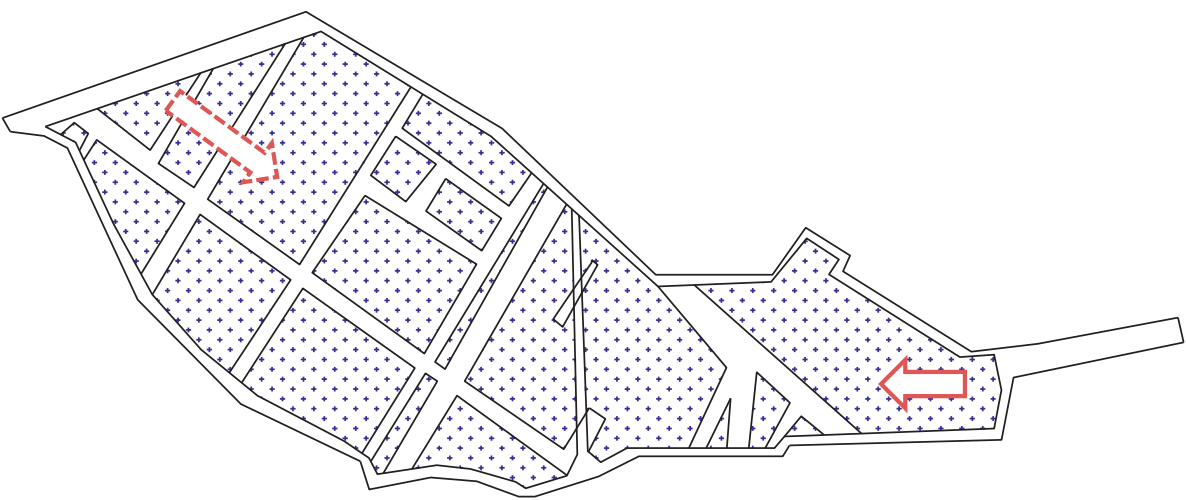

$\because \because \quad$ PBD area

Construction from the northwest end to the center of the site

Construction from the eastern end to the center of the site

(c)

Figure 2: Continued. 


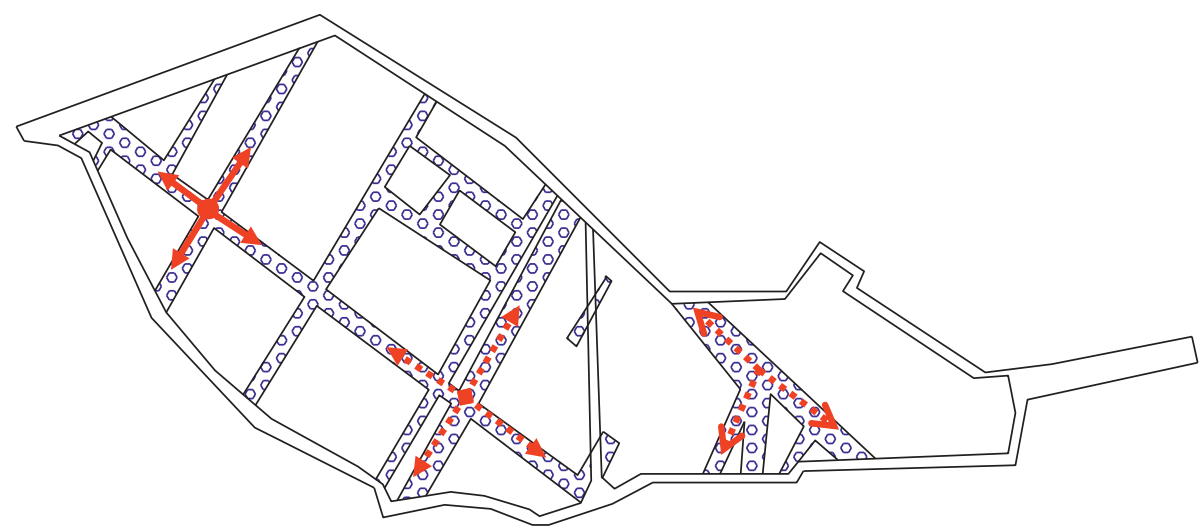

$$
\begin{aligned}
& \text { Construction sequence of the third } \\
& \text { group (4 sets) } \\
& \text { Construction sequence of the second } \\
& \text { group (4 sets) } \\
& \cdots \rightarrow \begin{array}{l}
\text { Construction sequence of the first } \\
\text { group (3 sets) }
\end{array}
\end{aligned}
$$

(d)
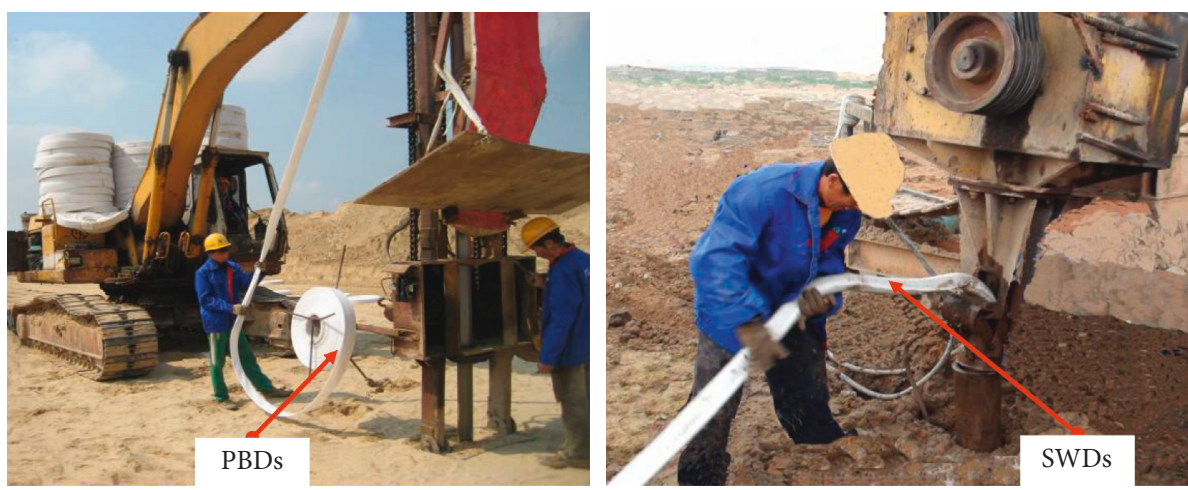

(e)

FIGURE 2: Layout sketch and construction sequence of CPVDs (PBDs and SWDs): (a) plan layout of plastic board drains (PBDs) and sand wick drains (SWDs) at test section; (b) schematic diagram of 1-1 cross section; construction sequence of (c) PBD area and (d) SWD area; (e) construction of two types of vertical drainage channels.

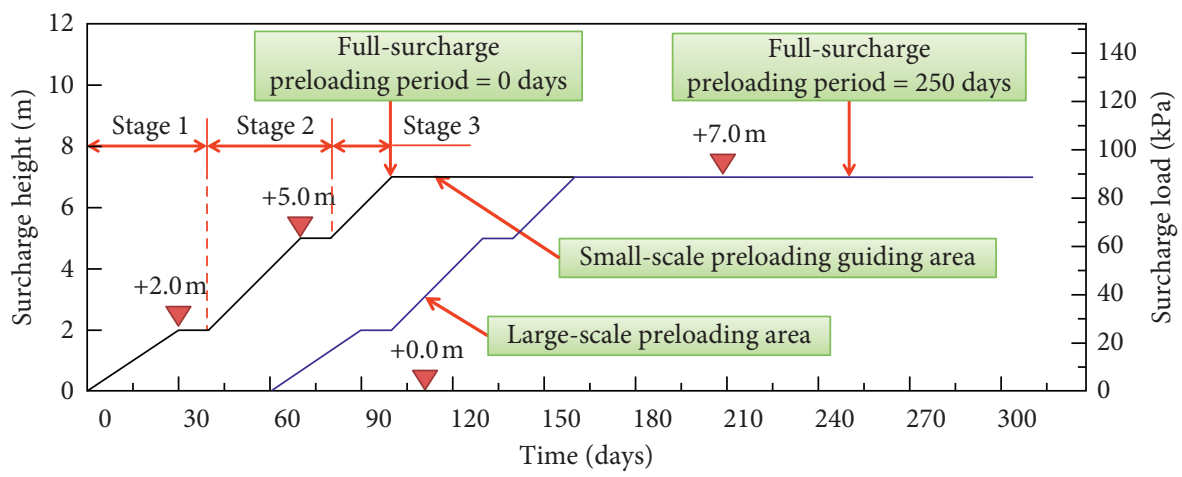

FIGURE 3: Concept of parallel construction sequence for stage loading surcharge.

in Figure 3, stage 1 surcharge loading was up to $38 \mathrm{kPa}(2.0 \mathrm{~m}$ fill height), stage 2 up to $95 \mathrm{kPa}$ (5.0 $\mathrm{m}$ fill height), and stage 3 up to $133 \mathrm{kPa}$ (7.0 $\mathrm{m}$ fill height). After the test site was loaded to a certain surcharge in the stage loading, a waiting period was needed in order to meet the settlement control standards for the marine soft soil foundation. The waiting period was 
10 days with a $38 \mathrm{kPa}$ surcharge, which was subsequently increased to $95 \mathrm{kPa}$. The design waiting period was also 10 days when the surcharge increased from 95 to $133 \mathrm{kPa}$. The foundation settlement control standards during the surcharge preloading are as follows: the average settlement of the foundation is not greater than $15 \mathrm{~mm} / \mathrm{d}$, the horizontal displacement is not greater than $5 \mathrm{~mm} / \mathrm{d}$, and the ratio of pore water pressure and the additional load value is not greater than 0.6. When the actual consolidation data are greater than the foundation settlement control standards, it should be considered to slow down the surcharge preloading speed.

4.3. Theoretical Calculation for Consolidation Degree. The theoretical calculation for consolidation degree was carried out in advance of the field installation of CPVDs and the surcharge placement works. The consolidation process with CPVDs usually involves both vertical flow $\left(C_{v}\right)$ and horizontal flow $\left(C_{h}\right)$, and each process can be calculated separately. Some analytical solutions have been proposed in the past few decades for consolidation of foundation improved by vertical drains. The consolidation problem of the soil was first proposed and analyzed by Terzaghi [19]. Barron [20] presented complete formulas for consolidation of a soil cylinder containing a central sand well drain. Hansbo $[21,22]$ recommended modifications to the solution which dealt with simplifying assumptions due to the smear effect and well resistance of the band-shaped prefabricated vertical drains. Onoue [23] put forward a simplified formula given below to calculate the average consolidation degree regarding the radial water flow, $U_{r}$ :

$$
\begin{gathered}
U_{r}=1-\exp \frac{-8 T_{r}}{F(n)+0.8 L}, \\
F(n)=\frac{n^{2}}{n^{2}-1} \ln (n)-\frac{3 n^{2}-1}{4 n^{2}},
\end{gathered}
$$

where $n$ is the drain spacing ratio and $n=d_{e} / d_{w} ; d_{e}$ is the effective drainage diameter of the equivalent soil cylinder of the vertical drain, equal to $1.05 l$ ( $l$ is the spacing of the two adjacent vertical drains in a triangle grid in this study); $d_{w}$ is the actual geometric diameter of the circular vertical drain or the equivalent diameter of the band-shaped vertical drain; in this study, $d_{w}=100 \mathrm{~mm}$ for the SWDs and $d_{w}=2(b+\delta) / \pi$ for the PBDs ( $b$ and $\delta$ are the width and thickness of the PBDs, respectively); $T_{r}$ is the time factor for consolidation by horizontal drainage, given by

$$
T_{r}=\frac{C_{h} t}{d_{e}^{2}}
$$

where $C_{h}$ is the coefficient of horizontal drainage consolidation. $L$ is the well resistance parameter developed by Yoshikuni and Nakanodo [24] and is given by

$$
L=\left(\frac{32}{\pi^{2}}\right)\left(\frac{k_{h}}{k_{w}}\right)\left(\frac{H}{d_{w}}\right),
$$

where $H$ is the vertical drainage length of the PVDs; $k_{h}$ and $k_{w}$ are the horizontal hydraulic conductivity of the soil and the coefficient of longitudinal permeability of the vertical drain, respectively. Taking the smear effect into consideration requires the following $F\left(n^{*}\right)$ to be substituted into drain factor $F(n)$ in Equation (2):

$$
F\left(n^{*}\right) \approx \ln \left(\frac{n}{s}\right)-0.75+\left(\frac{k_{h}}{k_{r}}\right) \ln (s),
$$

where the smear zone ratio $s=d_{s} / d_{w}$ and $d_{s}$ is the diameter of the smeared zone.

The equation applicable for calculation of consolidation degree due to vertical flow [9] is expressed as follows:

$$
U_{v}=\frac{\left(4 T_{v} / \pi\right)^{0.5}}{\left[1+\left(4 T_{v} / \pi\right)^{2.8}\right]^{0.178}}
$$

where $T_{v}$ is the time factor for consolidation by horizontal drainage and given by

$$
T_{v}=\frac{C_{v} t}{H^{2}}
$$

where $C_{v}$ is the coefficient of horizontal drainage consolidation.

Carrillo [25] derived an equation for the average consolidation degree of the combined vertical and radial flow, $U_{v r}$ :

$$
U_{v r}=1-\left(1-U_{v}\right)\left(1-U_{r}\right) .
$$

The above theoretical formulas for solving the consolidation problem have assumed that the soft soil foundation is suddenly loaded the surcharge. However, the surcharge is always applied to the soft foundation step by step in actual engineering. The consolidation-time relationship obtained according to the above theoretical method must be corrected. Therefore, based on the conventional consolidation theories, the Chinese technical code for ground treatment [26] specified the formula for calculating the average consolidation degree (i.e., Equation (9)) of the PVDs preloaded foundation under multistage loading conditions:

$$
\bar{U}_{t}=\sum_{i=1}^{n} \frac{\dot{q}_{i}}{\sum p}\left[\left(T_{i}-T_{i-1}\right)-\frac{\alpha}{\beta} e^{-\beta t}\left(e^{\beta T_{i}}-e^{\beta T_{i-1}}\right)\right],
$$

where $\bar{U}_{t}$ is the average consolidation degree of foundation at time $t ; \dot{q}_{i}$ is the surcharge loading rate of the $i$-th surcharge stage; $\sum p$ is the accumulation of load at all surcharge stages; $T_{i}$ and $T_{i-1}$ represent the starting and ending time of the $i$-th surcharge stage, respectively; $\alpha$ and $\beta$ are parameters determined according to the drainage consolidation conditions of the foundation soil, which are calculated according to the following equations, respectively:

$$
\begin{aligned}
& \alpha=\frac{8}{\pi^{2}}, \\
& \beta=\frac{8 C_{h}}{F(n) \cdot g d_{e}^{2}}+\frac{\pi^{2} C_{v}}{4 H^{2}} .
\end{aligned}
$$


The ground settlement $S_{t}$ for the CPVD-improved foundation can be calculated for the various surcharge heights by using

$$
S_{t}=S_{\infty} \bar{U}_{t},
$$

where $S_{t}$ and $S_{\infty}$ are the calculated settlement at time $t$ and the calculated ultimate settlement of the preloading foundation, respectively. The predicted curves for consolidation degree generated from the design of vertical drains with surcharge preloading for the CPVD-improved area are shown in Figure 4.

Figure 4 shows that it takes about 440 days for theoretical consolidation degree to reach more than $90 \%$ if the largescale fill preloading construction is carried out after the completion of the small-scale fill preloading tests. However, according to the parallel construction programme in smallscale guiding area and large-scale preloading area, it takes about 270 days for the consolidation degree to reach more than $90 \%$ of the theoretical calculation, and the construction period is shortened by about half a year.

\section{Field Monitoring and Assessment of Improvement Performance}

5.1. Field Monitoring System. In order to monitor the performance of the soft marine foundation both in surcharge filling period and preloading period, controlling the stability of the ground, inspecting the strengthening and preloading effect of the foundation, and guiding the design and construction, the in situ monitoring system was settled in the test site. The field monitoring system as shown in Figure 5 was set up to monitor surface and subsurface settlements, excess pore pressures, and lateral movements, and so on. The basic requirements for the monitoring system are listed as follows:

(1) Surface and Subsurface Settlements Monitoring. The surface settlement plates were installed to monitor the total settlement of the CPVD-improved foundation. In order to monitor the variation of the total settlement time, the surface settlement gauges should be embedded in the bottom of the sand fill blanket before the CPVDs were installed. The layered subsurface settlement rings were used to observe the compressions of the subsurface soil layers in different depths. Each observation point of the subsurface settlements requires setting a settlement ring in the upper, middle, and lower part of the silt layers and arranging a settlement ring in the stabilized sublayer.

(2) Pore Pressure Monitoring. The pore water pressure gauges were installed for monitoring the pore water pressure, the dissipation rate, and ground consolidation of the silt layers. Each pore water pressure monitoring point arranged three sensors which was located $1.0 \mathrm{~m}$ below the top surface, the middle part, and $1.0 \mathrm{~m}$ above the bottom of the silt layers, respectively, and the pore water pressure sensors in the different depth were embedded separately in different holes.
(3) Lateral Movement Monitoring around Improved Site. The inclinometer was used to detect the horizontal displacement of the embankment and cofferdam around the improved site. Arul et al. [27] pointed out that inclinometers should install vertically in a borehole socketed to the firm/dense stratum. Therefore, the inclinometer pipes had a spacing of about $70 \mathrm{~m}$ and the bottom of the pipes was buried more than $3 \mathrm{~m}$ in the underlying layer which is not deformed during the consolidating. Moreover, the settlement monitoring points were laid around the existing high-voltage tower.

(4) Observation frequency. The settlement, excess pore water pressure, and lateral movements were monitored at a close interval in the filling surcharge period and at a wider interval during the full-surcharge preloading period. When the monitoring devices have been buried in the test site, the initial readings of the instrumentations were recorded once. Then, the readings were measured once every 2 to 3 days before the filling surcharge. During the filling surcharge construction period, from the filling stage 1 to the end of stage 3 , it was observed once a day. And after that, it was recorded once per three days during the full-surcharge preloading period. The observation interval may be appropriately extended with the decrease of the settlement velocity until the settlement was stable.

5.2. Layout of Field Monitoring Instrumentation. Details of the arrangement of the instruments are shown in Figure 5. The plan layout of the monitoring points is shown in Figure 5(a). Both the vertical and horizontal spacing of the surface settlement monitoring points are $75 \mathrm{~m}$, and the total number of the surface settlement monitoring points is not less than 70. In addition, there are 15 measuring points for subsurface settlements in deep soil layer and 26 measuring points for pore water pressure. A section of the arrangement of the instruments is shown in Figure 5(b); a total of 2 inclinometer pipes, 6 surface settlement plates, 8 layered subsurface settlement rings, and 9 pore water pressure gauges were set up in this section. Protective devices were provided in the exposed parts of the observation instruments, and strict protection measures were taken during the filling construction to ensure the continuity of observation data.

\subsection{Settlement Characteristics}

5.3.1. Surface Settlement. A typical settlement characteristic is shown in Figure 6 as taken from measuring points T52 and T53 for surface settlements. The maximum settlement of the ground surface at T52 and T53 is $105.23 \mathrm{~cm}$ and $75.75 \mathrm{~cm}$, respectively. T52 and T53 are far apart from each other (75 meters). There are differences in physical and mechanical properties such as soil compression, drainage, and strength of the stratum, which may be the possible reason for the differential settlement between the two measuring points. 


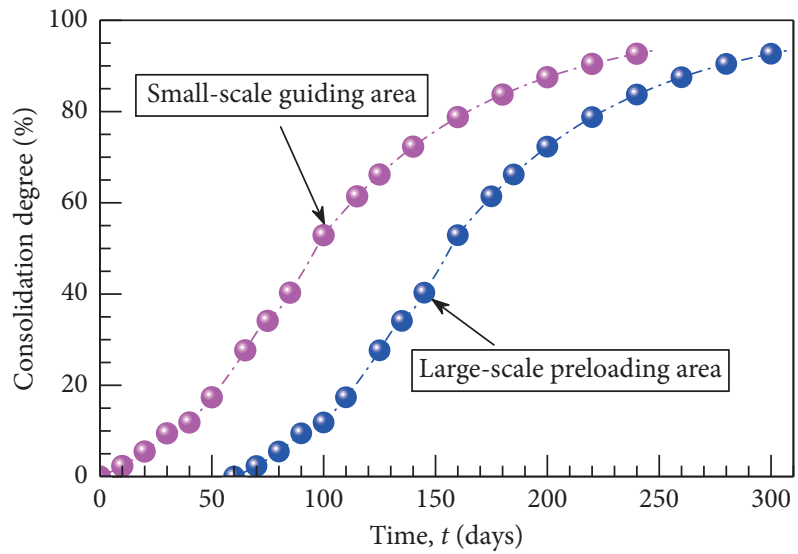

FIgURE 4: Theoretical calculated curves of time-consolidation degree for CPVD-improved soft ground.

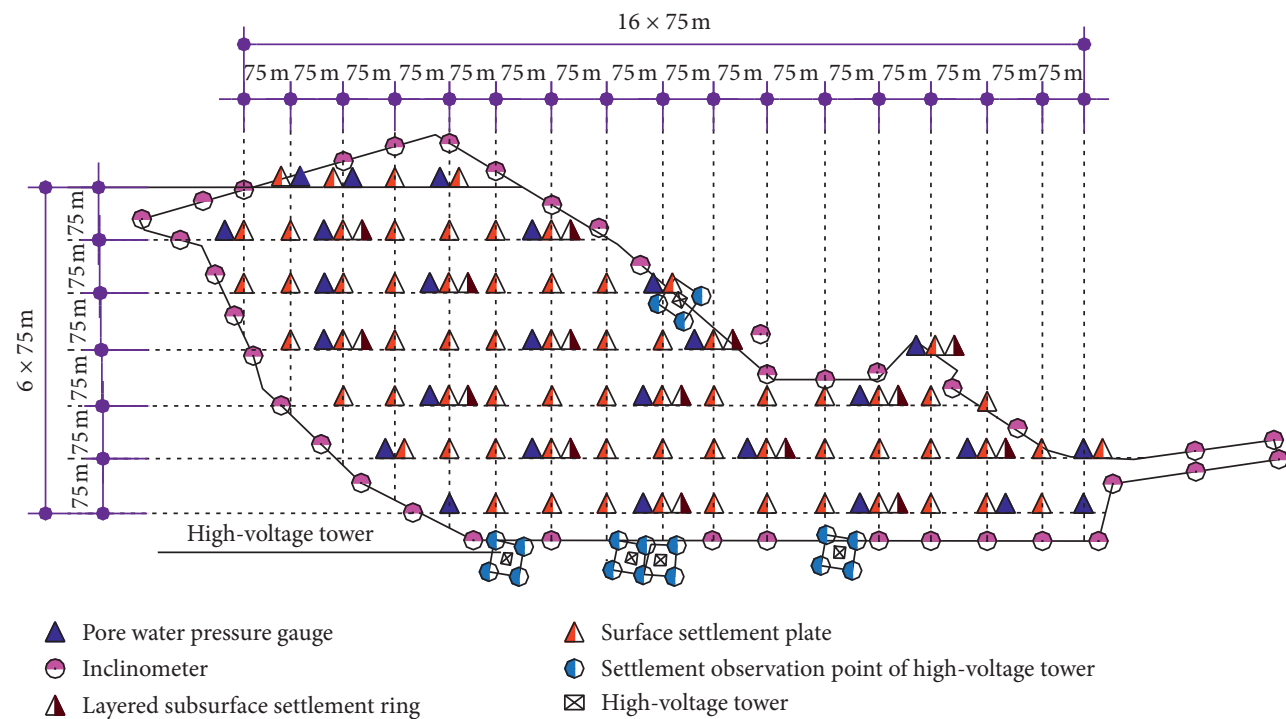

(a)

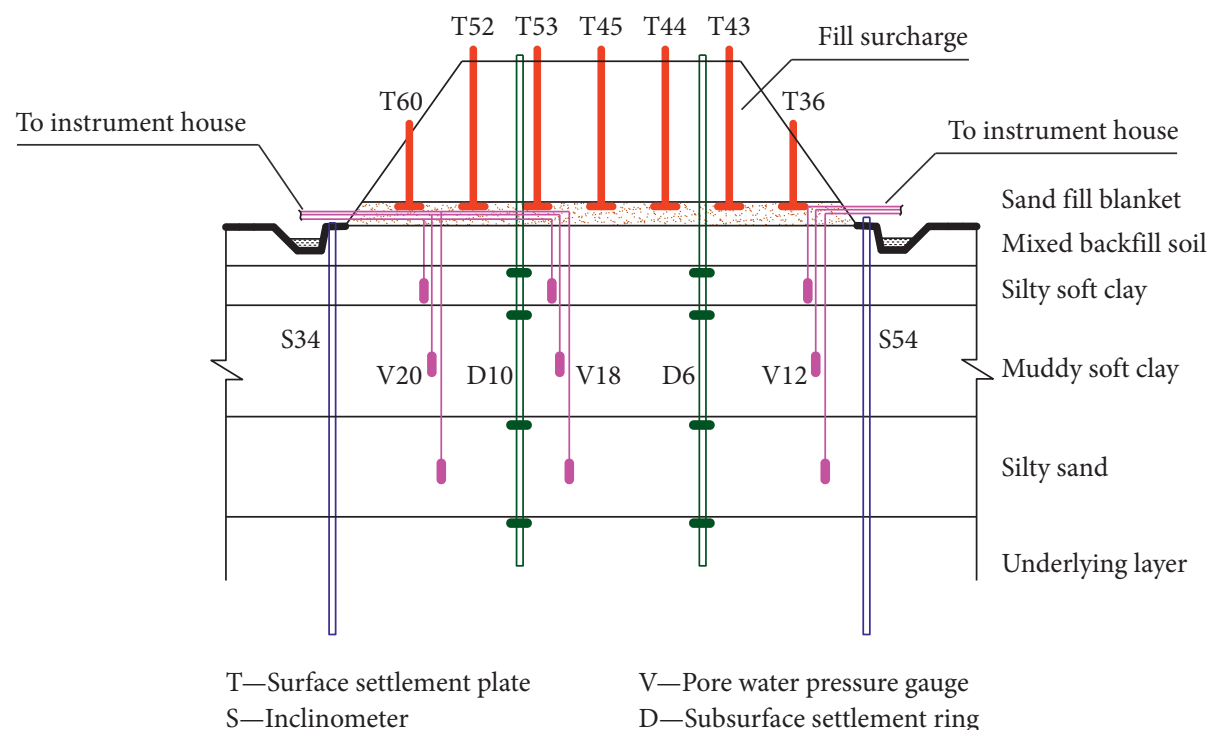

(b)

FIGURE 5: Sketch map of field test systems and monitoring instrumentation layout: (a) plan layout of field monitoring instrumentation; (b) a typical cross-sectional sketch map of field monitoring instrumentation. 


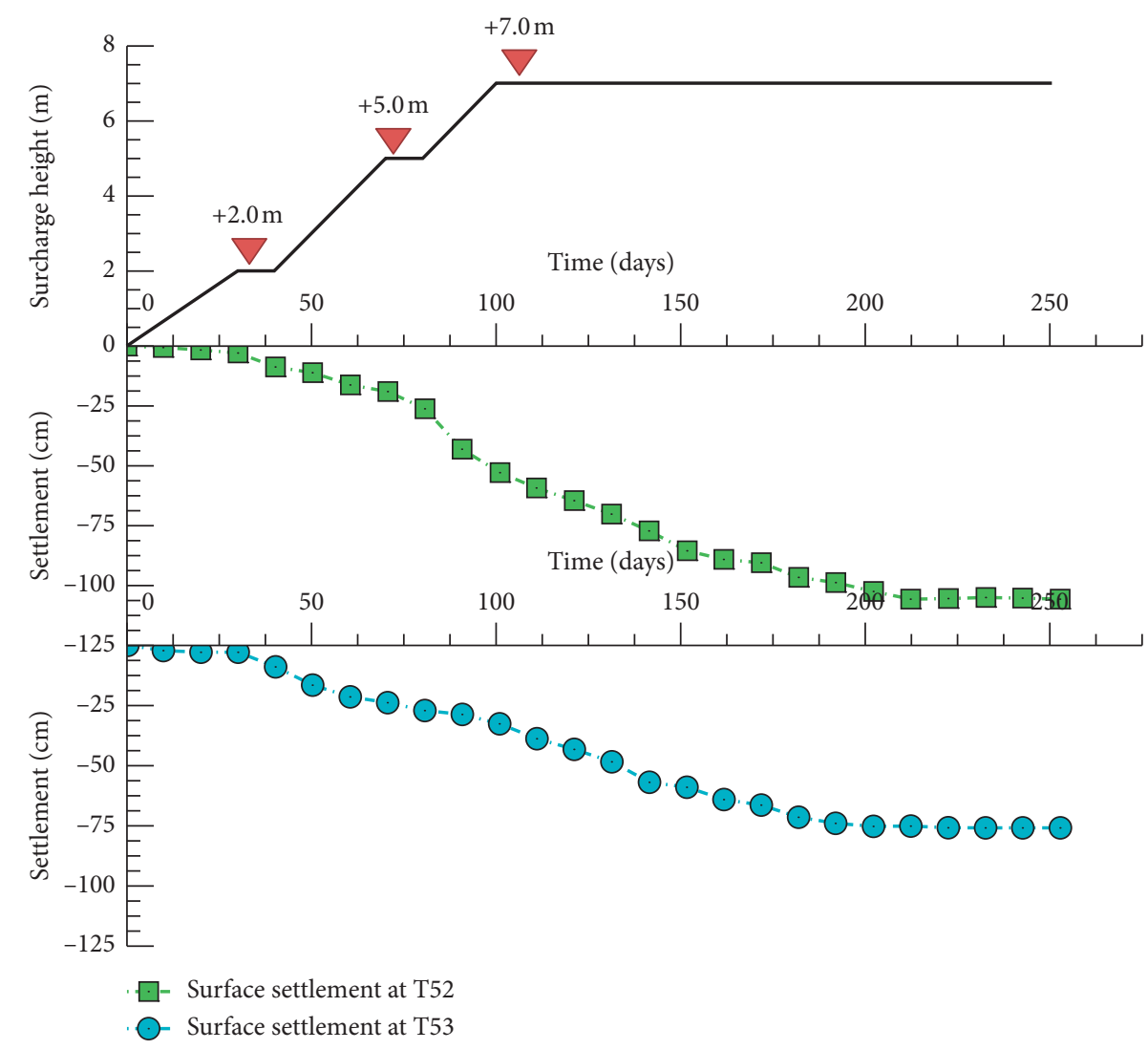

FIgURE 6: Measured curves of surface settlement at T52 and T53: surcharge-time-settlement curves.

Field monitoring shows that although there is differential settlement between T52 and T53, it does not lead to foundation and slope instability. It can be seen from Figure 6 that the settlement curve of the CPVD-improved soft foundation is gentle and close to linear change and its consolidation settlement is not noticeable in the early stage of preloading after the installation of the PBDs and SWDs, which means that the PBDs and SWDs only increase vertical drainage channels for the soft soil, and the purpose of accelerating the consolidation of the soft foundation cannot be achieved if proper fill surcharge is not imposed. With the increase of the surcharge height, the consolidation settlement of the soft ground increases considerably and the settlement curves show a multistage development. The settlement curves will become steeper at the beginning of each stage of surcharge load, and this trend gets smaller with the increase of the surcharge preloading times. The settlement curves develop gradually in approximately a parabolic manner with the preloading time increasing until the next surcharge loaded. During the full-load preloading period after the completion of all the surcharge stages, the settlement curves gradually slow down and become stable finally.

Figure 7 is a comparison chart of the surface settlement of measuring point T45 and T44, improved by SWDs and PBDs, respectively. It can be seen from Figure 7 that the surface settlement of both SWDs and PBDs drainage area increases with the increasing of surcharge height. Under the same preloading condition, the surface settlement of the soft foundation in the SWD-treated area (e.g., measuring point T45) is later than that of the PBD-treated area (e.g., measuring point T44); the PBD-treated site has a maximum settlement of $98.24 \mathrm{~cm}$, but the largest settlement of the SWD-treated area is $88.4 \mathrm{~cm}$. It indicates that the total settlement of the SWD-treated area is less than that of PBDtreated area, and the differential settlements for the same area may depend upon the horizontal spacing and performance of the two different vertical drainage channels despite the formation having the same thickness and same parameter (the designed horizontal drainage spacing is $1.2 \mathrm{~m}$ and $1.6 \mathrm{~m}$ for PBDs and SWDs, respectively). To reduce the differential settlements, further researches will be needed about the reasonable horizontal space of PBDs and SWDs. After 150 days' preloading drainage consolidation from the end of the third surcharge stage, the surface settlement of the PBD-treated area (e.g., measuring point T44) and the SWDtreated area (e.g., measuring point T45) increased by $68.6 \%$ and $54.9 \%$, respectively, indicating that the soft ground has been effectively consolidated by the CPVDs incorporating the fill surcharge preloading method.

5.3.2. Subsurface Settlement. The measured subsurface settlement curves of surcharge-time-settlement of measuring point D10 at different depth are shown in Figure 8. As illustrated in Figure 8, the subsurface settlement of the soft foundation increases with the increase of surcharge loading 


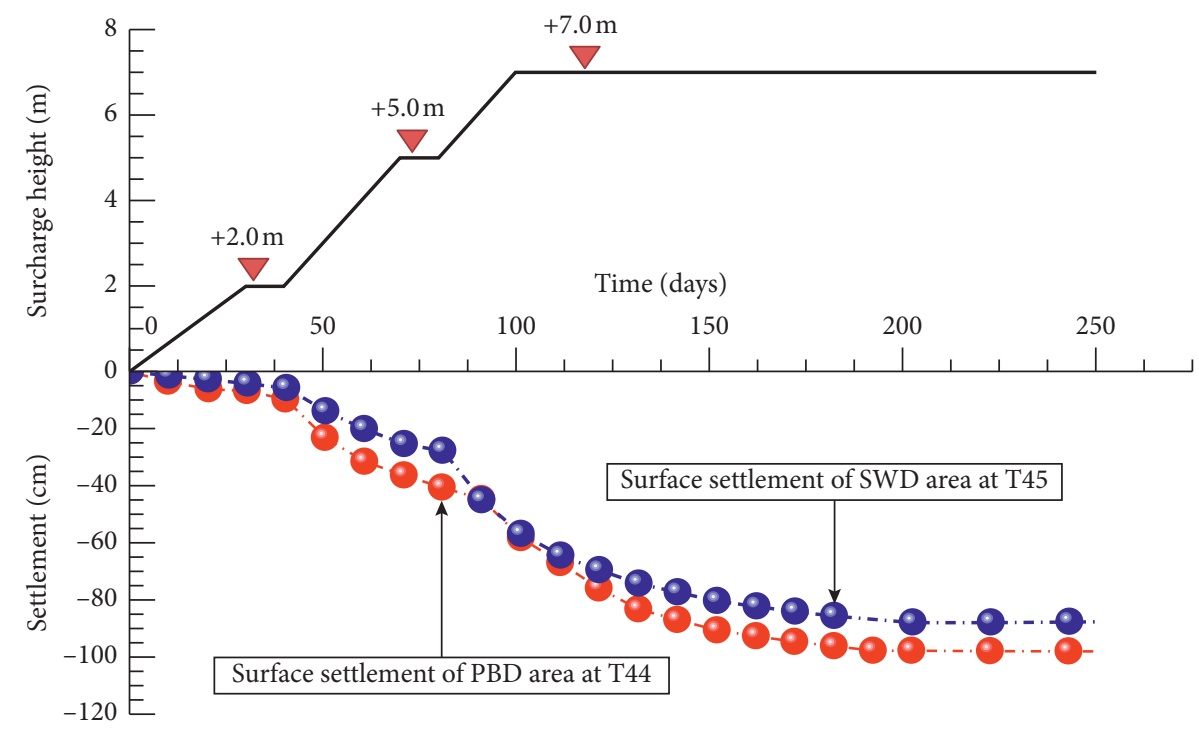

FIGURE 7: Comparisons of surface settlement of soft soil foundation treated by PBDs and SWDs: surface settlement comparison for T44 and T45.

and is less than that of surface settlement. Moreover, the maximum subsurface settlement existed on top of the soft layer and the value is $52.38 \mathrm{~cm}$, which is about half of the settlement recorded in the shallow layer. The amount of compression in deep soft soil layers decreases with increasing soil layer's depth, indicating that the consolidation compression of the upper part of the deep soft soil layer should be larger than that of the lower parts. For example, the measured consolidation in the mixed backfill soil, the silty soft clay, the muddy soft clay, and the silty sand are $22.62 \mathrm{~cm}, 19.51 \mathrm{~cm}, 10.59 \mathrm{~cm}$, and $5.39 \mathrm{~cm}$, respectively. Moreover, the maximum compression of the underlying layer at measuring point D10 is $16.67 \mathrm{~cm}$, which indicates that the underlying layer is fully compressed. In order to ensure the drainage consolidation effect of the underlying layer, the influence of the underlying layer on the settlement of the soft foundation should be taken into account.

Figure 9 is a subsurface settlement comparison diagram about PBD- and SWD-treated area. According to Figure 9, the subsurface settlement of the soft foundation in PBD or SWD area increases with the increase of surcharge loading. Furthermore, the subsurface settlement in the PBD area is larger than that in the SWD area during the same consolidation time or at the same surcharge loading condition, meaning that the settlement velocity rate in soft ground treated with PBDs is larger than the one treated with SWDs. The PBD method has a good effect on shortening the preloading duration time, but the subsurface settlement is not obvious in the later stage of preloading, and it is difficult to predict the postconstruction settlement and the creep settlement of the improved soft foundation. The subsurface settlement of the foundation treated by SWDs is more moderate, and there is more obvious settlement tendency in the later stage of preloading, but the preloading time needed for stabilizing the consolidation settlement of the soft foundation is longer than the PBD method.
5.4. Lateral Displacement Characteristics. The lateral displacement curves with depth of the improved soft foundation at inclinometer measuring point S34 and S54 are shown in Figure 10. The inclinometer S54 was located at the innermost edge of the original solid embankment which is the main construction road. The displacement change at S54 was affected by the passing vehicles, and the influence in the surface layers is more significant than in the deep layers. The maximum horizontal displacement of the top of the inclinometer S54 is $11 \mathrm{~mm}$ as shown in Figure 10(a), which shows that the effect of surcharge preloading on the safe service of the existing embankment structure is small. The inclinometer S34 was installed at the boundary of the improved soft foundation site. The top displacement of the inclinometer S34 is negative, which indicates that the improved ground moved to the preloading area, and the movement amount increased with increasing the preloading time and surcharge load. The horizontal displacement of the subsurface layer at S34 also increases with the increase of the preloading time and surcharge load, and the maximum horizontal displacement is $70.6 \mathrm{~mm}$ which occurred at a depth of $8 \mathrm{~m}$ below the improved ground in the very soft soil layers. Moreover, the maximum deformation rate is $1.4 \mathrm{~mm} /$ $\mathrm{d}<5 \mathrm{~mm} / \mathrm{d}$, which meets the design requirements. The lateral displacement curves of the soft soil layer at depth of $3 \mathrm{~m}$ below the ground are quasiparabolic, and the soil was squeezed out of the preloading area. In addition, most of the lateral movements occurred at depths of $5 \sim 11 \mathrm{~m}$ below the ground. Furthermore, the horizontal displacement at the bottom of inclinometer pipe is close to zero, which indicated that the buried depth of the inclinometer pipe was reasonable and met the project monitoring requirements. The growth rate of the horizontal displacement of the soft foundation slowed down after the completion of the third stage surcharge, and the horizontal displacement was stabilized after two months of full surcharge preloading. 


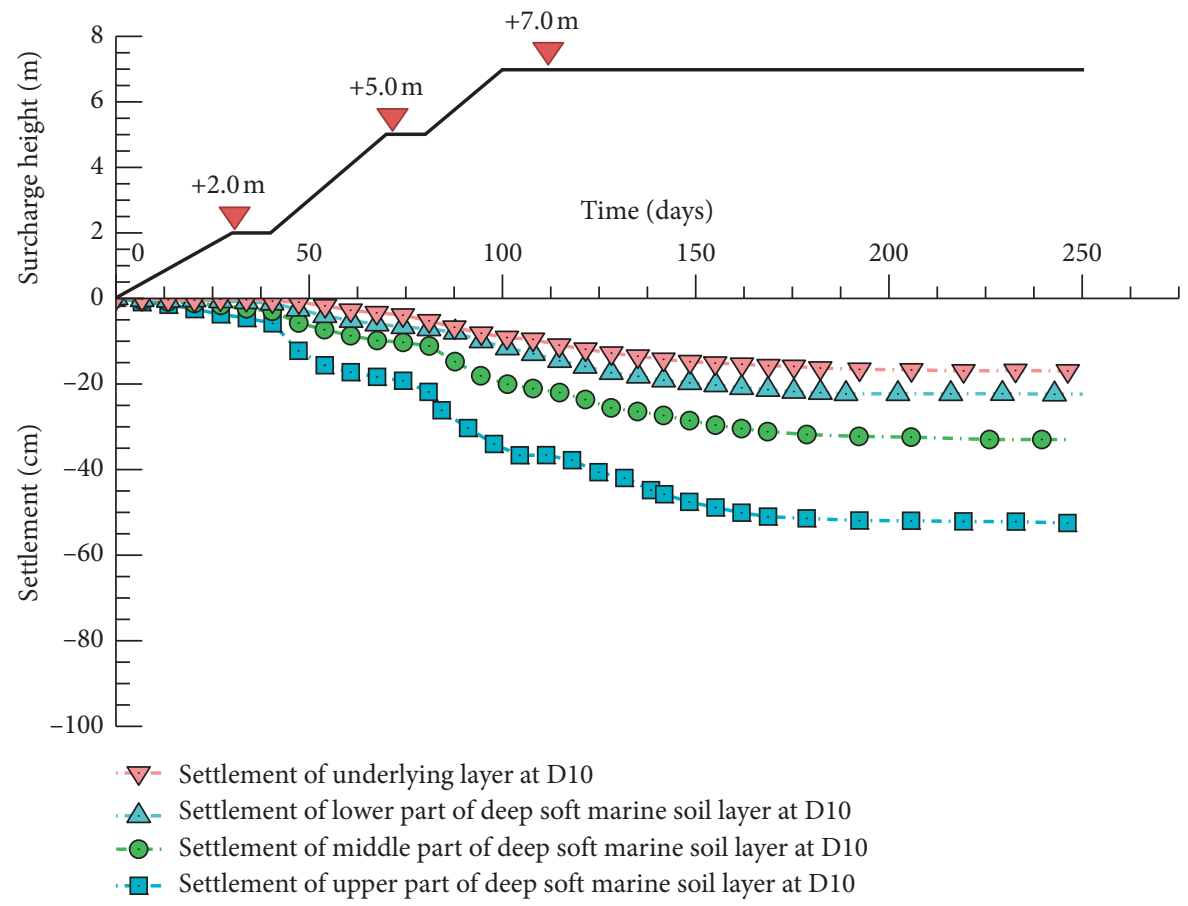

FIGURE 8: Surcharge-time-subsurface settlement curves at D10 measuring point.

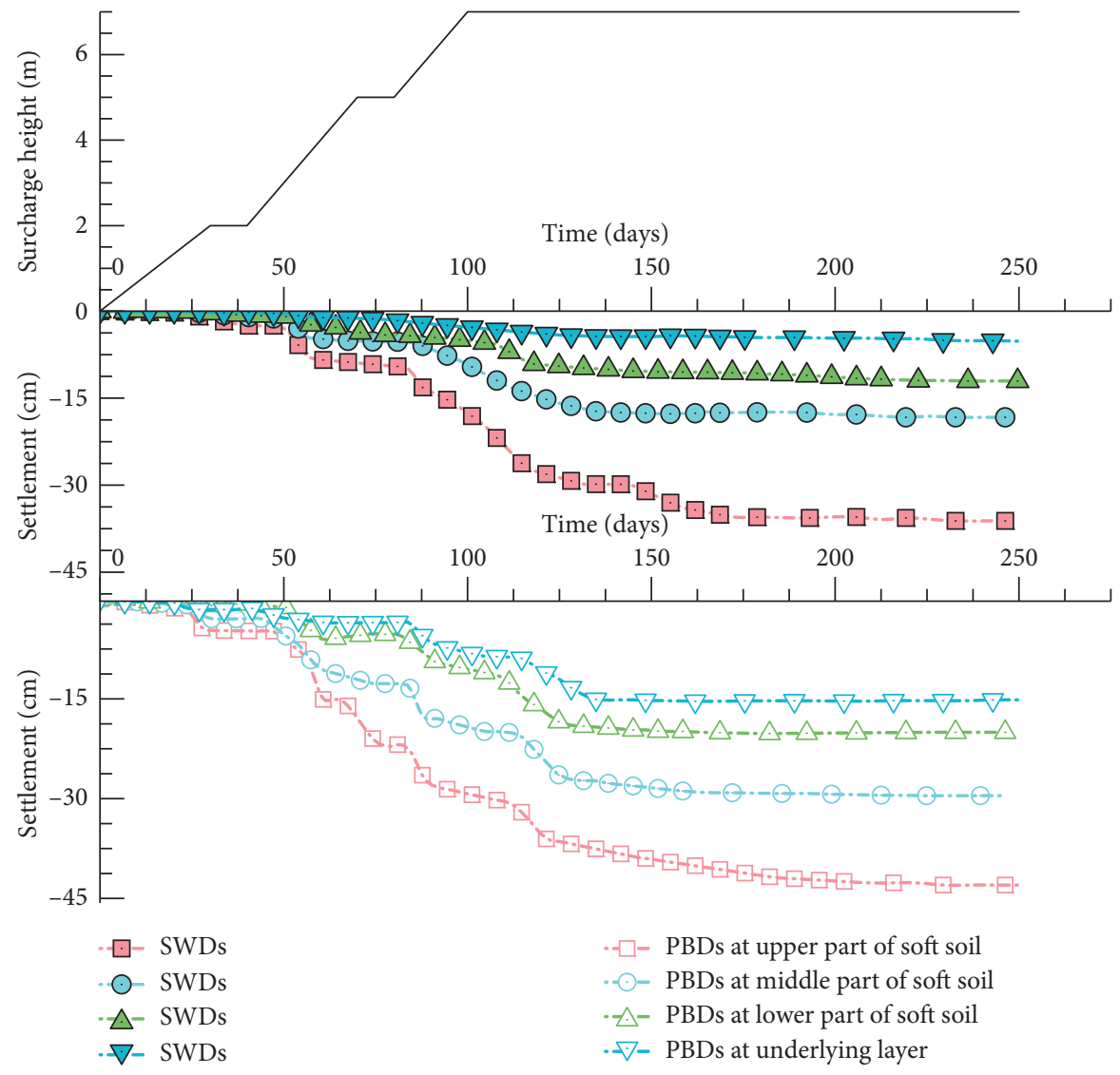

FIGURE 9: Comparison of subsurface settlement of soft soil foundation treated by PBDs and SWDs. 


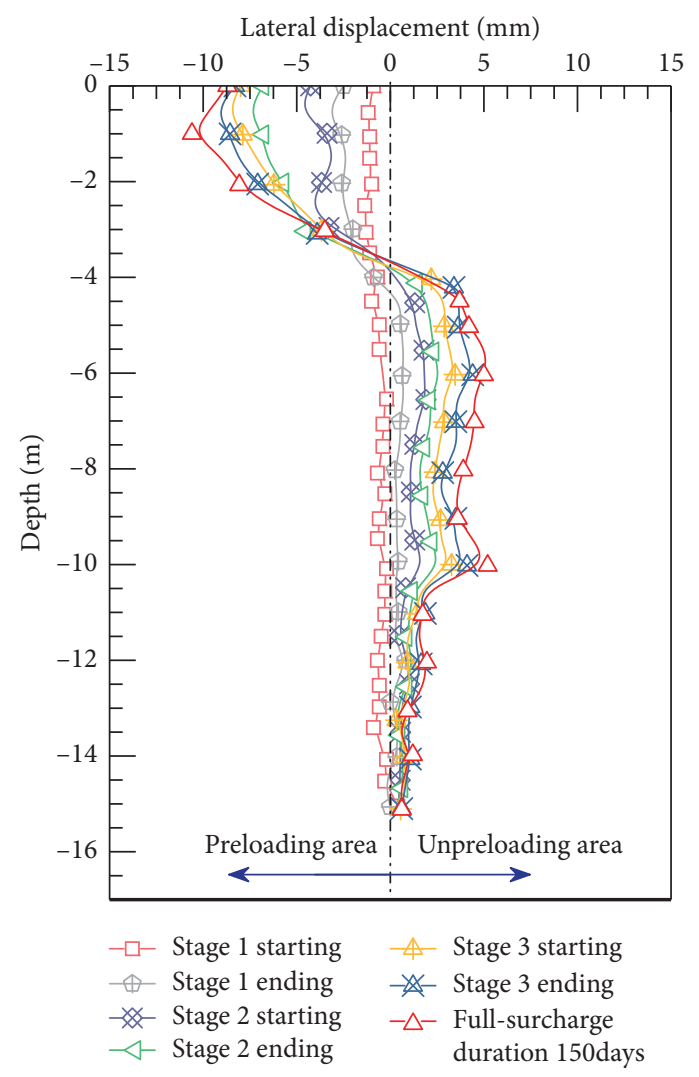

(a)

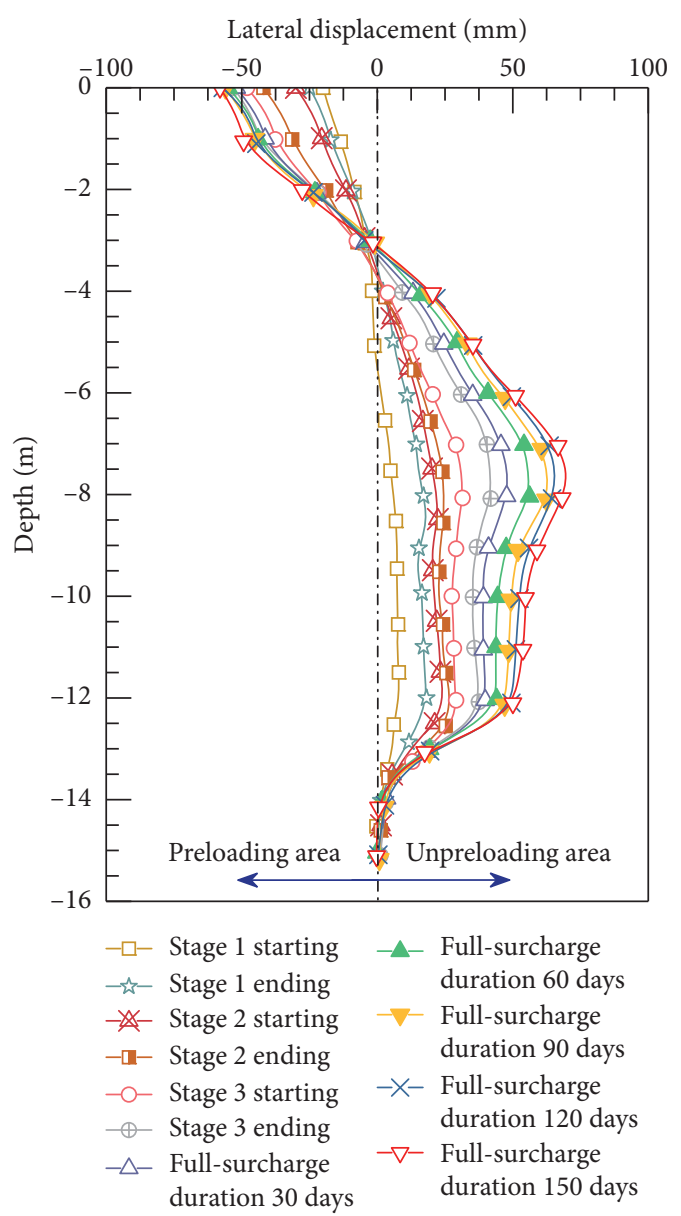

(b)

FIGURE 10: Lateral displacement with depth at improved soft foundation: (a) lateral displacement with depth at S54; (b) lateral displacement with depth at S34.

5.5. Dissipation Features of Excess Pore Water Pressure. Figure 11 shows the curves of the excess pore water pressure at different depths of the PBDs and the SWD areas varying with surcharge height and time. It is observed that the excess pore water pressure in the soft soil layers increases rapidly during each stage of surcharge and dissipates gradually during the standing period after each stage of surcharge and the preloading consolidation period after the third stage of surcharge, and finally closes to zero, indicating that the effective stress of the improved foundation is enhanced significantly and the CPVDs incorporating fill surcharge preloading are very effective in improving such complex soft soil foundation. Furthermore, the excess pore water pressure of the soft foundation dissipates slowly at the early stage of surcharge, and the dissipating rate of the pore water pressure is accelerated after the surcharge height is more than $5 \mathrm{~m}$, which further indicates that the accelerated consolidation effect of the soft foundation is not obvious when the surcharge load is small. The variations of excess pore pressure in different depths of the soft soil layers are similar, but the undulation of the excess pore pressure curves of the upper part of the soft soil layer is the smallest, followed by the lower part and the middle part. Moreover, the excess pore water pressure in the upper part of the soft soil layer is the smallest, the lower part is the second, and the middle part is the largest. It shows that the drainage effect of the upper part of the soft soil layer is better than that of the middle and lower parts in the surcharging and preloading consolidation processes. It is mainly because the upper part of the soft soil layer is close to the sand cushion, which makes the excess pore pressure dissipate rapidly when the surcharge load was applied. The PBDs and SWSs penetrate through the soft layers into the underlying permeable sand layer, so that the excess pore water pressure in the lower part of the soft layer can also dissipate quickly. The medium part of the soft layers has the longest drainage path, so its excess pore water pressure dissipates slowest. In addition, the excess pore water pressure in the $\mathrm{PBD}$ area is larger than that in the SWD area and the dissipation period of excess pore water pressure in the PBD area is slightly longer than that in the SWD area. 


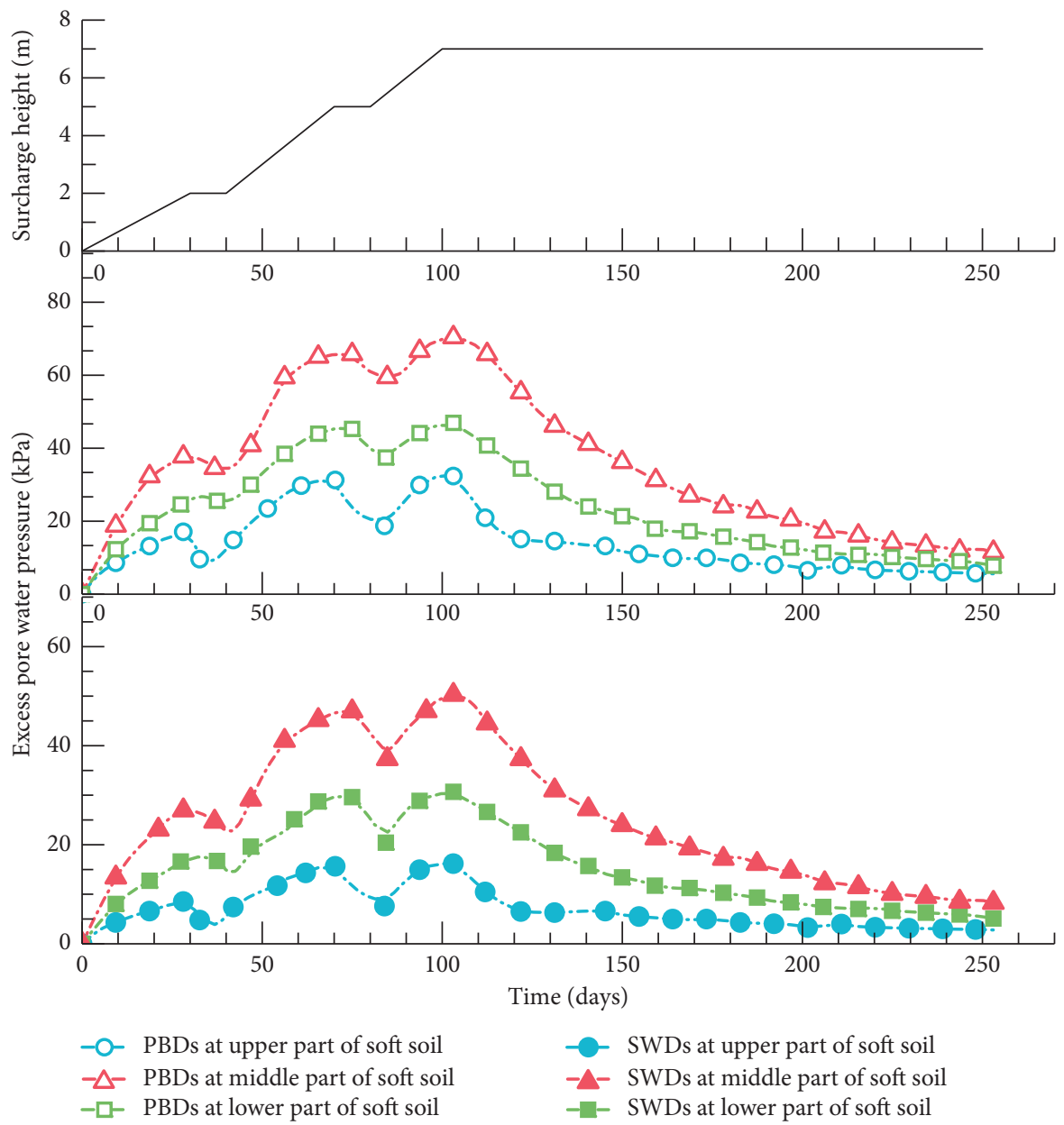

FIGURE 11: Time-surcharge-excess pore water pressure curves of soft foundation treated by CPVDs.

\section{Prediction of Ultimate Settlement and Consolidation Degree Based on Field Instrumentation Data}

Due to the difficulty to thoroughly survey the geological situation of the site, the accuracy of physical and mechanical parameters of the foundation soil, and other uncertainties, the foundation settlement based on theoretical calculation is often different from the actual settlement. The more accurate ultimate settlements were predicted using the field settlement results by applying a prediction method, such as the Asaoka method [28] and hyperbolic method [29-31]. The hyperbolic method has become one of the most convenient and commonly used methods for predicting the ultimate ground settlement based on available field data [9, 32-38]. In the hyperbolic method, the relationship between consolidation settlement $S_{t}$ and time $t$ is postulated to approach a hyperbolic curve and the straight-line portion of the curve of $(t / S)$ versus $t$ can be represented by the following equation [32]

$$
\frac{t}{S_{t}}=\alpha^{*}+\beta^{*} t
$$

where $\alpha^{*}$ and $\beta^{*}$ are the intercept and the slope of the straight-line segment of the curve of $(t / S)$ versust, respectively. These two constants can easily be obtained by regression analysis once sufficient field data is available. In this study, in order to extend the capability of prediction of hyperbolic model under multistage loading conditions, Equation (13) is presented in the following modified form after the coordinate translation and the formula for calculating the settlement at time $t$ in full-surcharge preloading period is

$$
\frac{t-t_{0}}{S_{t}-S_{0}}=\alpha^{*}+\beta^{*}\left(t-t_{0}\right)
$$

This is the equation of a straight line in a plot of $\left(t-t_{0} / S_{t}-S_{0}\right)$ against $\left(t-t_{0}\right)$, where $S_{0}$ is the measured settlement of the improved foundation at the full-surcharge preloading initial time $t_{0}$ (Figure 12).

Rearranging terms of Equation (14), the ground settlement $S_{t}$ at any time $t$ in full-surcharge preloading period can be rewritten as

$$
S_{t}=S_{0}+\frac{t-t_{0}}{\alpha^{*}+\beta^{*}\left(t-t_{0}\right)}
$$




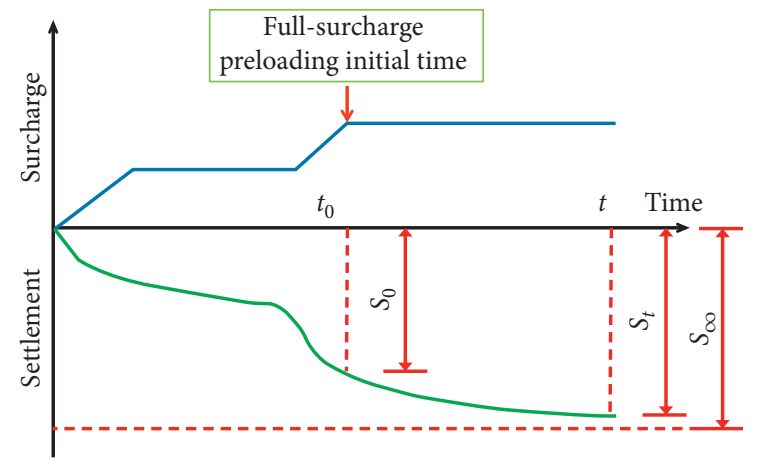

Figure 12: Prediction of settlement by the modified hyperbolic method under multistage loading conditions.

Taking the limits of Equation (15) as $t \longrightarrow \infty$, the ultimate settlement $S_{\infty}$ is given by $1 / \beta^{*}$ which is the reciprocal of the slope of the straight-line portion of the curve of $\left(t-t_{0} / S_{t}-S_{0}\right)$ versus $\left(t-t_{0}\right)$; therefore, the ultimate settlement $S_{\infty}$ and the postconstruction settlement $S$ could be defined as follows:

$$
\begin{gathered}
S_{\infty}=S_{0}+\frac{1}{\beta^{*}}, \\
S=S_{\infty}-S_{\mathrm{te}},
\end{gathered}
$$

where $S_{\text {te }}$ are the measured total settlement at the ending time of the full-surcharge preloading.

Figure 13 presents the typical degree of settlementhyperbolic curves about $\left(t-t_{0} / S_{t}-S_{0}\right)$ versus $\left(t-t_{0}\right)$ for the surface settlement test data of T44, T45, T52, and T53 by applying the hyperbolic method. It can be observed from Figure 11 that the slope of the straight-line portion of the hyperbolic curves for T44, T45, T52, and T53 is 0.0221, $0.0278,0.0179$, and 0.021 , respectively. Combining Equation (16) and Figure 12, the estimates of ultimate settlement $S_{\infty}$ and postconstruction settlement $S$ of the CPVDimproved ground are determined as shown in Table 2. It is found that the average postconstruction settlement at T44, T45, T52, and T53 is $1.24 \mathrm{~cm}$. According to the Chinese Code for Design of Railway Earth Structure (TB 10001-2016, J 447-2016) [39], the controlled limits of subgrade postconstruction settlement for high-speed railway $(250 \mathrm{~km} / \mathrm{h})$ and intercity railway $(200 \mathrm{~km} / \mathrm{h})$ are $10 \mathrm{~cm}$ and $15 \mathrm{~cm}$, respectively. Consequently, it indicates that the soft marine foundation improved by the CPVD system is suitable for the construction of high-speed railway and intercity railway.

Due to the absence of field-instrumentation-based settlement data, in the engineering design stage, the ultimate settlement of the foundation was usually estimated by the soil's laboratory compression experimental data and the layer-by-layer summation method [26] defined as follows:

$$
S_{\infty}=\xi S_{c}=\xi \sum_{i=1}^{n} \frac{e_{0 i}-e_{1 i}}{1+e_{0 i}} h_{i},
$$

or

$$
S_{\infty}=\xi S_{c}=\xi \sum_{i=1}^{n} \frac{p_{i}}{E_{s i}} h_{i}
$$

where $S_{c}$ is the vertical primary consolidation settlement calculated by layer-by-layer summation method; $e_{0 i}$ and $e_{1 i}$ are the void ratio corresponding to the soil self-weight stress at the middle point of the $i$-th soil layer and the void ratio corresponding to the sum of the soil self-weight stress and the additional stress at the midpoint of the $i$-th soil layer, respectively; $h_{i}$ is the thickness of the $i$-th soft soil layer; $p_{i}$ is the additional stress at the midpoint of the $i$-th soil layer; $E_{s i}$ is compressive modulus of the $i$-th soft soil layer; and $\xi$ is a comprehensive empirical coefficient to consider the shear deformation of the foundation and other factors, and it might be determined by the following equation based on the vertical primary consolidation settlement $S_{c}$ and the hyperbolic-method-predicted ultimate settlement $S_{\infty}$ :

$$
\xi=\frac{S_{\infty}}{S_{c}} .
$$

For example, the empirical coefficient $\xi$ calculated by Equation (19) for T44, T45, T52, and T53 is 1.48, 1.45, 1.36, and 1.42 , respectively. Therefore, the empirical coefficient $\xi$ is recommended to be 1.35 1.50 for the CPVD-improved marine soft ground.

By rewriting Equation (12), the formula for calculating the average consolidation degree $\bar{U}_{t}$ at time $t$ based on the measured settlement data can be written as $\bar{U}_{t}=S_{t} / S_{\infty}$, where $S_{t}$ and $S_{\infty}$ are the field observed total settlement at time $t$ and the hyperbolic-method-predicted ultimate settlement, respectively. Figure 14 shows the back-up analysis results of the consolidation degree based on the measured field settlement. It is observed that the consolidation degree determined from the hyperbolic-method-predicted ultimate settlement and the measured field settlement data is underestimated by that predicted by applying the Terzaghi theory when the consolidation degree of the foundation is more than $45 \% \sim 72 \%$. In addition, the average underestimated values of consolidation degree for T52, T53, T44, and $\mathrm{T} 45$ are $6.58 \%, 5.54 \%, 9.35 \%$, and $10.24 \%$, respectively.

\section{Conclusions}

This paper presents a case study on using the CPVDs incorporating fill preloading for marine soft ground improvement at the site of an intercity express railway project in China. A modified form of the hyperbolic model is proposed for predicting the ultimate settlement of the marine soft ground under multistage fill surcharge loading conditions and subsequently for estimating the ultimate settlement, postconstruction settlement, and the consolidation degree. The main conclusions are as follows:

(1) Field monitoring shows that the CPVDs incorporating the fill preloading method have good improvement effect in complex marine soft ground 


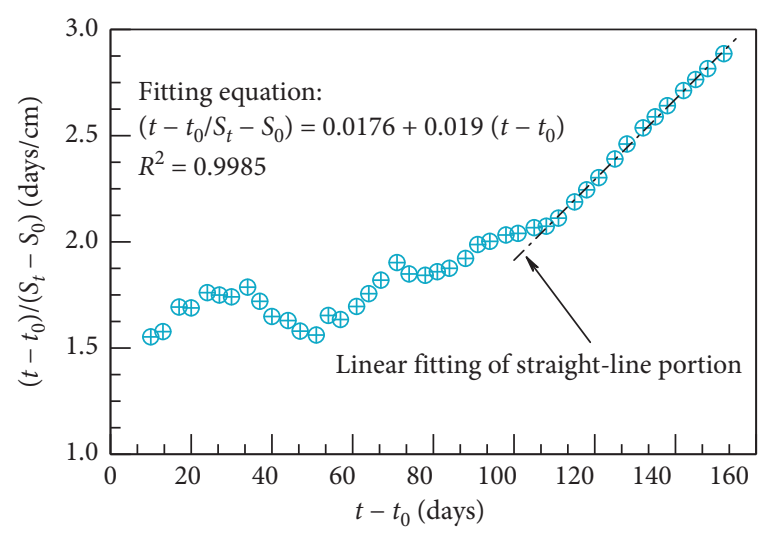

$\oplus$ T52 test data

(a)

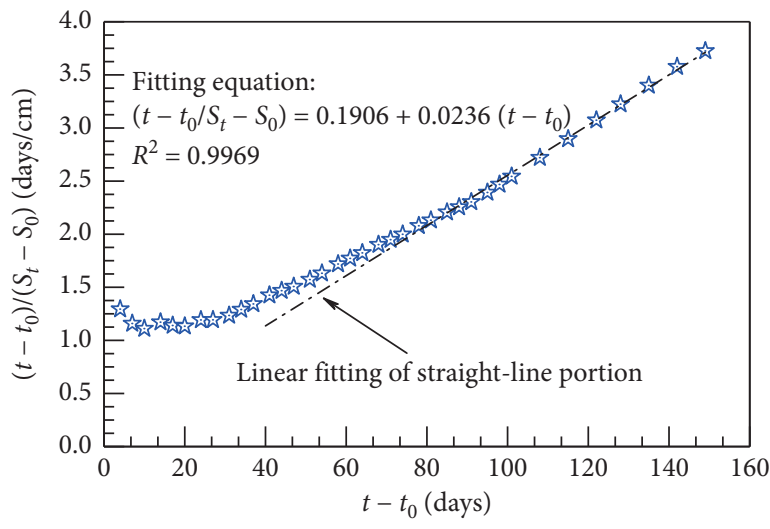

is T44 test data

(c)

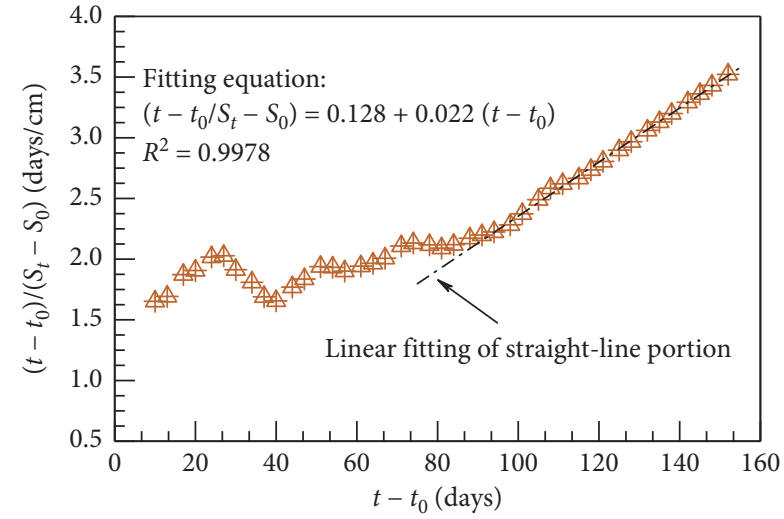

453 test data

(b)

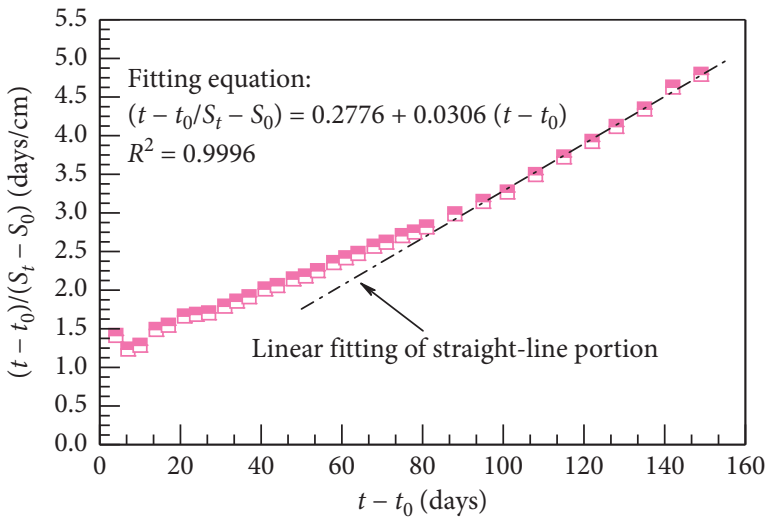

- T45 test data

Figure 13: Hyperbolic plots for ground settlement of (a) T52, (b) T53, (c) T44, and (d) T45.

TABLE 2: Summary of estimates of settlements from the hyperbolic plots.

\begin{tabular}{|c|c|c|c|c|c|c|c|c|}
\hline \multirow{2}{*}{$\begin{array}{l}\text { Settlement observation } \\
\text { point }\end{array}$} & \multirow{2}{*}{$\begin{array}{c}\text { Vertical } \\
\text { drain } \\
\text { type }\end{array}$} & \multirow{2}{*}{$\begin{array}{c}\text { Drain } \\
\text { spacing } \\
(\mathrm{m})\end{array}$} & \multicolumn{4}{|c|}{$\begin{array}{l}\text { Hyperbolic estimate of ultimate } \\
\text { settlement } S_{\infty}\end{array}$} & \multirow{2}{*}{$\begin{array}{l}\text { Observed maximum settlement } S_{\text {te }} \\
\qquad(\mathrm{cm})\end{array}$} & \multirow{2}{*}{$\begin{array}{l}\text { Postconstruction } \\
\text { settlement } S(\mathrm{~cm})\end{array}$} \\
\hline & & & $\alpha^{*}$ & $\beta^{*}$ & $R^{2}$ & $\begin{array}{c}S_{\infty} \\
(\mathrm{cm})\end{array}$ & & \\
\hline T44 & PBDs & 1.2 & 0.1906 & 0.0236 & 0.9969 & 100.33 & 98.24 & 2.09 \\
\hline T45 & SWDs & 1.6 & 0.2776 & 0.0306 & 0.9996 & 89.44 & 88.40 & 1.04 \\
\hline T52 & PBDs & 1.2 & 0.0176 & 0.0190 & 0.9985 & 105.30 & 105.23 & 0.07 \\
\hline T53 & PBDs & 1.2 & 0.1280 & 0.0223 & 0.9978 & 77.51 & 75.75 & 1.76 \\
\hline
\end{tabular}

because this new method can accelerate the consolidation of marine soft ground, improve ground stability, and effectively control the postconstruction settlement. Furthermore, the effect of fill preloading on the safe service of the existing embankment structure at the edge of the site is not obvious.

(2) The prediction of settlement based on field instrumentation data shows that the average postconstruction settlement of the marine soft ground improved by CPVD system is much smaller than the design standard of high-speed railway $(250 \mathrm{~km} / \mathrm{h})$ and intercity railway $(200 \mathrm{~km} / \mathrm{h})$. Therefore, the complex marine soft ground improved by the CPVD system is suitable for the construction of intercity express railway and high-speed railway.

(3) The improvement construction period of complex marine soft ground will be greatly shortened by the parallel construction programme in small-scale guiding area and large-scale preloading area.

(4) The consolidation degree obtained by the classical consolidation theory is in good agreement with that predicted by the measured field settlement data and 


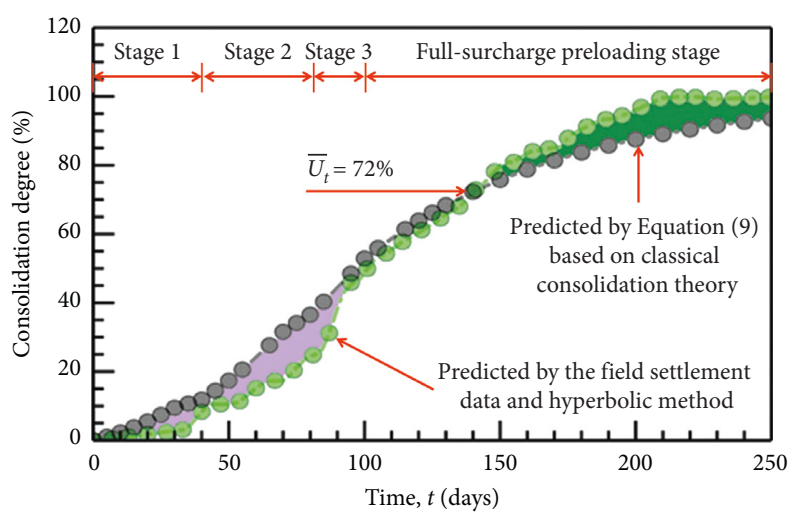

(a)

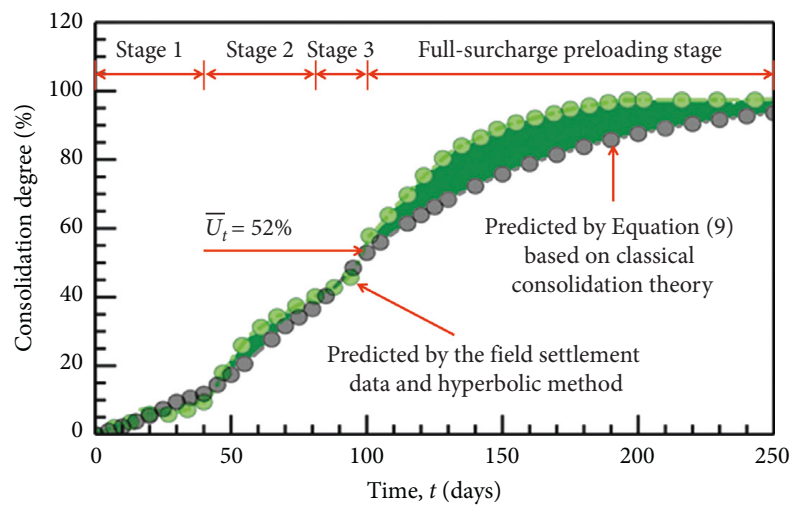

(c)

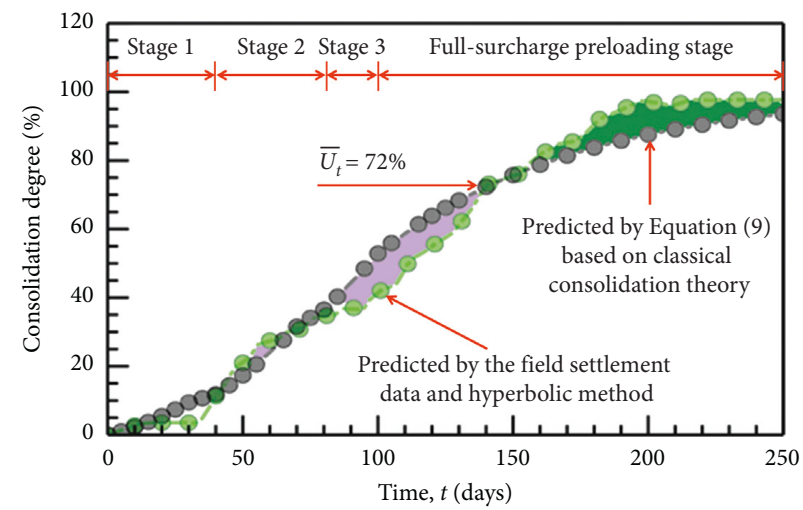

(b)

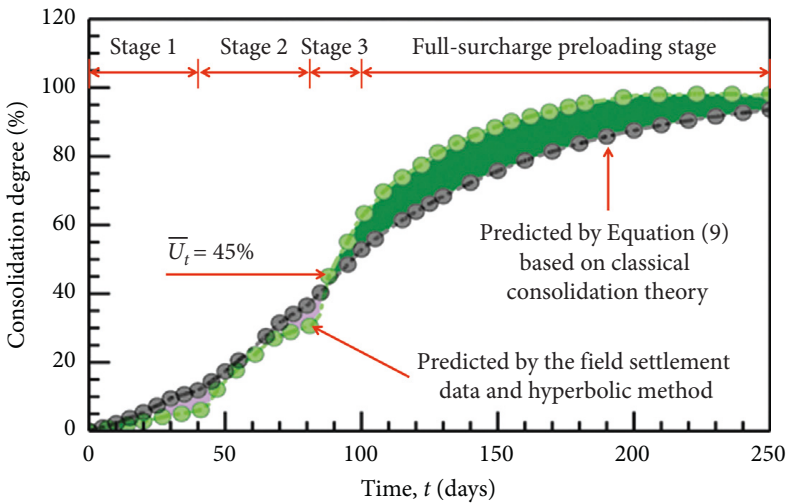

(d)

FIgURe 14: Curves of predicted consolidation degree versus time for (a) T52, (b) T53, (c) T44, and (d) T45.

the modified hyperbolic method except when the average consolidation is $45 \% \sim 72 \%$. The comprehensive empirical coefficient in the layer-by-layer summation method used to estimate the ultimate settlement at the engineering design stage is recommended to be 1.35 1.50 for the CPVD-improved marine soft ground.

\section{Data Availability}

The data used to support the findings of this study are included within the article.

\section{Conflicts of Interest}

The authors declare that they have no conflicts of interest.

\section{Acknowledgments}

This research was funded by the project of the Natural Science Foundation of Hunan Province, China (grant no. 2017JJ2021).

\section{References}

[1] P. Mincheol, "A study on the improvement effect and field applicability of the deep soft ground by ground heating method," Applied Sciences, vol. 8, no. 6, pp. 852-868, 2018.
[2] W. Zhu, J. Yan, and G. Yu, "Vacuum preloading method for land reclamation using hydraulic filled slurry from the sea: a case study in coastal China," Ocean Engineering, vol. 152, pp. 286-299, 2018.

[3] J.-F. Xue, J.-F. Chen, J.-X. Liu, and Z.-M. Shi, "Instability of a geogrid reinforced soil wall on thick soft Shanghai clay with prefabricated vertical drains: a case study," Geotextiles and Geomembranes, vol. 42, no. 4, pp. 302-311, 2014.

[4] T. Zhang, X. Yue, Y. Deng, D. Zhang, and S. Liu, "Mechanical behaviour and micro-structure of cement-stabilised marine clay with a metakaolin agent," Construction and Building Materials, vol. 73, no. 3, pp. 51-57, 2014.

[5] Y.-B. Deng, G.-B. Liu, M.-M. Lu, and K.-h. Xie, "Consolidation behavior of soft deposits considering the variation of prefabricated vertical drain discharge capacity," Computers and Geotechnics, vol. 62, no. 8, pp. 310-316, 2014.

[6] J. Wang, J. Ma, F. Liu et al., "Experimental study on the improvement of marine clay slurry by electroosmosis-vacuum preloading," Geotextiles and Geomembranes, vol. 44, no. 4, pp. 615-622, 2016.

[7] D. T. Bergado, A. S. Balasubramaniam, R. J. Fannin, and R. D. Holtz, "Prefabricated vertical drains (PVDs) in soft Bangkok clay: a case study of the new Bangkok International Airport project," Canadian Geotechnical Journal, vol. 39, no. 2, pp. 304-315, 2002.

[8] J. Chu, M. Bo, and V. Choa, "Improvement of ultra-soft soil using prefabricated vertical drains," Geotextiles and Geomembranes, vol. 24, no. 6, pp. 339-348, 2006.

[9] M. W. Bo, A. Arulrajah, and H. Nikraz, "Preloading and prefabricated vertical drains design for foreshore land 
reclamation projects: a case study," Proceedings of the Institution of Civil Engineers-Ground Improvement, vol. 11, no. 2, pp. 67-76, 2007.

[10] K.-W. Liu and R. K. Rowe, "Numerical modelling of prefabricated vertical drains and surcharge on reinforced floating column-supported embankment behaviour," Geotextiles and Geomembranes, vol. 43, no. 6, pp. 493-505, 2015.

[11] G. Ye, Q. Zhang, Z. Zhang, and H. Chang, "Centrifugal modeling of a composite foundation combined with soilcement columns and prefabricated vertical drains," Soils and Foundations, vol. 55, no. 5, pp. 1259-1269, 2015.

[12] M. W. Bo, A. Arulrajah, S. Horpibulsuk, M. Leong, and M. Leong, "Quality management of prefabricated vertical drain materials in mega land reclamation projects: a case study," Soils and Foundations, vol. 55, no. 4, pp. 895-905, 2015.

[13] A. L. Welker and K. M. Herdin, "Evaluation of four equivalent diameter formulations for prefabricated vertical drains using flow rates," Geosynthetics International, vol. 10, no. 3, pp. 103-109, 2003.

[14] H. Abuel-Naga and A. Bouazza, "Equivalent diameter of a prefabricated vertical drain," Geotextiles and Geomembranes, vol. 27 , no. 3, pp. 227-231, 2009.

[15] H. M. Abuel-Naga, A. Bouazza, and D. T. Bergado, "Numerical assessment of equivalent diameter equations for prefabricated vertical drains," Canadian Geotechnical Journal, vol. 49, no. 12, pp. 1427-1433, 2012.

[16] E. Cascone and G. Biondi, "A case study on soil settlements induced by preloading and vertical drains," Geotextiles and Geomembranes, vol. 38, no. 3, pp. 51-67, 2013.

[17] D. Basu and M. Prezzi, "Design of prefabricated vertical drains considering soil disturbance," Geosynthetics International, vol. 16, no. 3, pp. 147-157, 2015.

[18] C. Huang, Y. Deng, and F. Chen, "Consolidation theory for prefabricated vertical drains with elliptic cylindrical assumption," Computers and Geotechnics, vol. 77, pp. 156-166, 2016.

[19] K. Terzaghi, "Der grundbruch an stauwerken und seine verhutung," Die Wasserkraft, vol. 17, no. 24, pp. 445-449, 1925.

[20] R. A. Barron, "Consolidation of fine-grained soils by drain wells," Transactions of ASCE, vol. 113, no. 2346, pp. 718-754, 1948.

[21] S. Hansbo, "Consolidation of clay by band-shaped prefabricated drains," Ground Engineering, vol. 12, no. 5, pp. 16-25, 1979.

[22] S. Hansbo, "Consolidation of fine-grained soils by prefabricated drains," in Proceedings of the 10th International Conference on Soil Mechanics and Foundation Engineering, vol. 3, pp. 677-682, Stockholm, Sweden, June 1981.

[23] A. Onoue, "Consolidation by vertical drains taking well resistance and smear into consideration," Soils and Foundations, vol. 28, no. 4, pp. 165-174, 1988.

[24] H. Yoshikuni and H. Nakanodo, "Consolidation of soils by vertical drain wells with finite permeability," Soils and Foundations, vol. 14, no. 2, pp. 35-46, 1974.

[25] N. Carrillo, "Simple two and three dimensional case in the theory of consolidation of soils," Journal of Mathematics and Physics, vol. 21, no. 1-4, pp. 1-5, 1942.

[26] Industry standard of the People's Republic of China JGJ 792012, Technical Code for Ground Treatment of Buildings, China Construction Industry Press, Beijing, China, 2013.

[27] A. Arulrajah, M. W. Bo, J. Chu et al., "Instrumentation at the Changi land reclamation project, Singapore," Proceedings of the Institution of Civil Engineers-Geotechnical Engineering, vol. 162, no. GE1, pp. 33-40, 2009.

[28] A. Asaoka, "Observational procedure of settlement prediction," Soils and foundations, vol. 18, no. 4, pp. 87-101, 1978.

[29] S. A. Tan, "Ultimate settlement by hyperbolic plot for clays with vertical drains," Journal of Geotechnical Engineering, vol. 119, no. 5, pp. 950-956, 1993.

[30] S. Tan, "Validation of hyperbolic method for settlement in clays with vertical drains," Soils and Foundations, vol. 35, no. 1, pp. 101-113, 1995.

[31] T. S. Tan, T. Inoue, and S. L. Lee, "Hyperbolic method for consolidation analysis," Journal of Geotechnical Engineering, vol. 117, no. 11, pp. 1723-1737, 1991.

[32] S. A. Tan, "Hyperbolic method for evaluation of settlement of ground pretreated by drains and surcharge," Geotechnical Engineering, vol. 25, no. 1, pp. 75-89, 1994.

[33] S. A. Tan, "Hyperbolic method for settlements in clays with vertical drains," Canadian Geotechnical Journal, vol. 31, no. 31, pp. 125-131, 1994.

[34] M. A. Al-Shamrani, "Applicability of the rectangular hyperbolic method to settlement predictions of sabkha soils," Geotechnical and Geological Engineering, vol. 22, no. 4, pp. 563-587, 2004.

[35] M. A. Al-Shamrani, "Applying the hyperbolic method and $\mathrm{C}_{\alpha} /$ $\mathrm{C}_{\mathrm{c}}$ concept for settlement prediction of complex organic-rich soil formations," Engineering Geology, vol. 77, no. 1-2, pp. 17-34, 2005.

[36] A. Arulrajah, H. Nikraz, and M. W. Bo, "Observational method of assessing improvement of marine clay," Ground Improvement, vol. 8, no. 4, pp. 151-169, 2004.

[37] H. I. Ling, D. Leshchinsky, Y. Mohri et al., "Estimation of municipal solid waste landfill settlement," Journal of Geotechnical \& Geoenvironmental Engineering, vol. 124, no. 8, pp. 21-28, 1998.

[38] R. N. Hwang and Z. C. Moh, "Prediction of long-term settlements induced by shield tunneling," Journal of Geoengineering, vol. 1, no. 2, pp. 63-70, 2006.

[39] Industry standard of the People's Republic of China TB 10001-2016, J 447-2016, Code for Design of Railway Earth Structure, China Railway Publishing House, Beijing, China, 2017. 


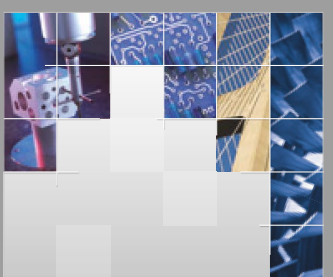

\section{Enfincering}
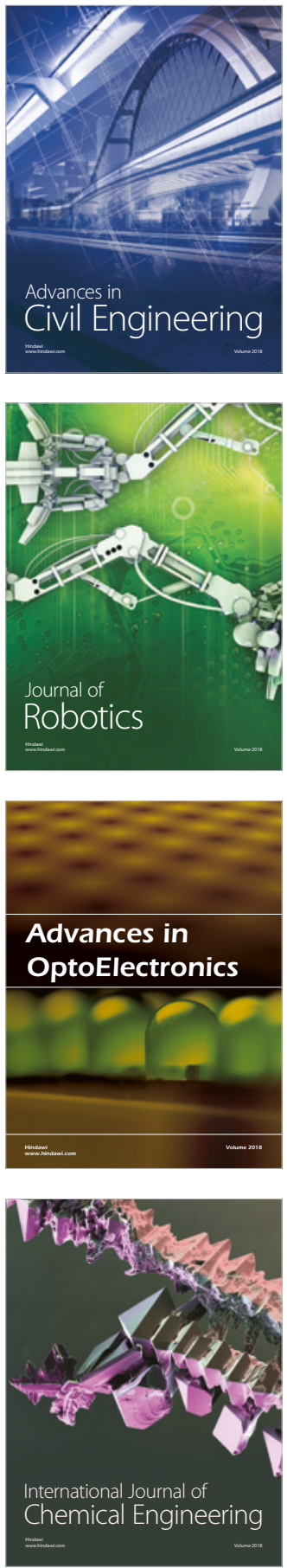

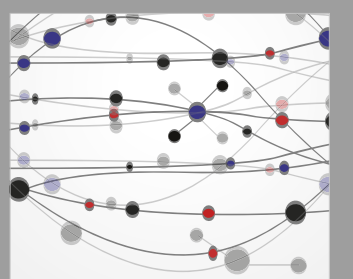

\section{Rotating \\ Machinery}

The Scientific World Journal

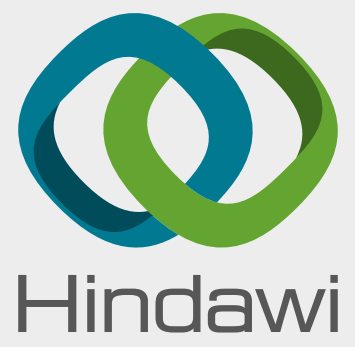

Submit your manuscripts at

www.hindawi.com
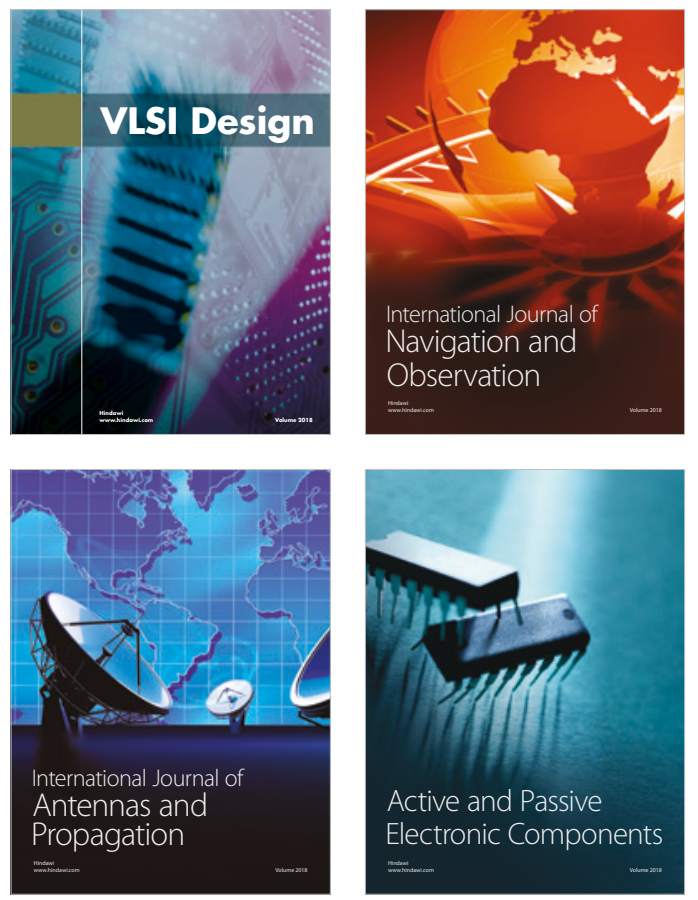
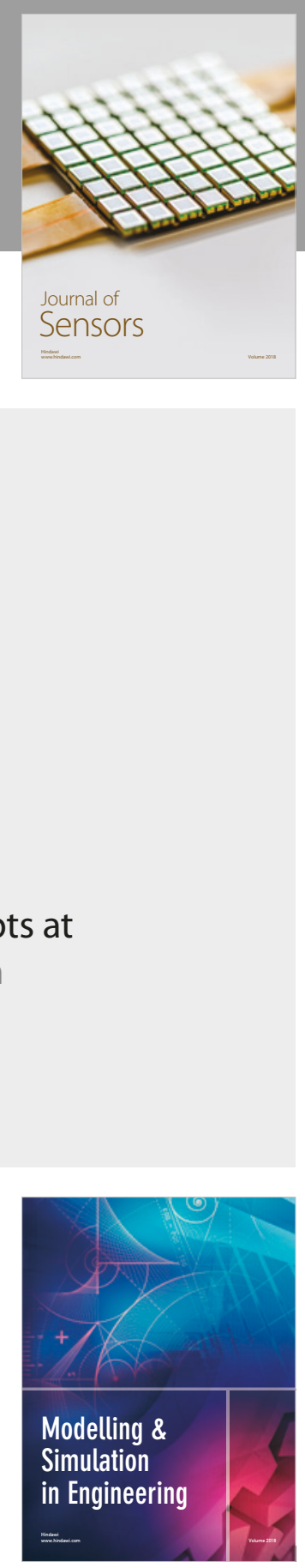

\section{Advances \\ Multimedia}
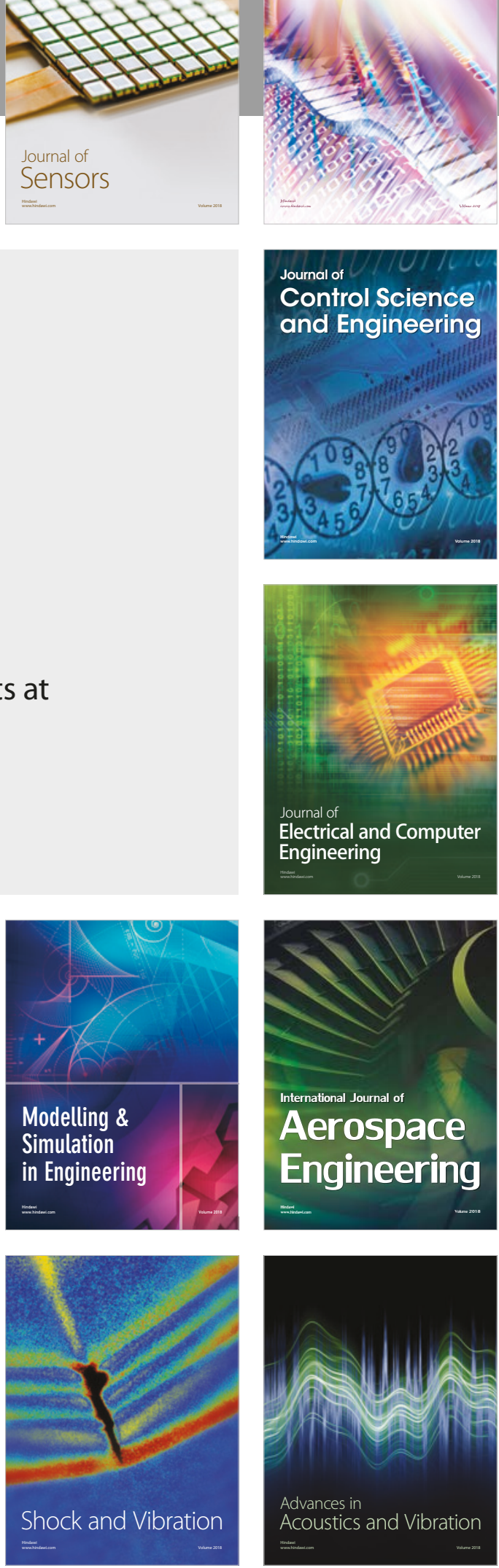